\title{
VARÍAVEIS HIDROSSEDIMENTOLÓGICAS E NÍVEIS DE DEGRADAÇÃO AMBIENTAL A PARTIR DE PROTOCOLOS DE AVALIAÇÃO RÁPIDA DE RIOS, ENTRE A BAÍA DA PALHA E O SADAO NO CORREDOR FLUVIAL DO RIO PARAGUAI
}

\author{
HYDROSYSSEDIMENTOLOGICAL VARIABLES AND LEVELS OF ENVIRONMENTAL DEGRADATION FROM \\ RAPID EVALUATION PROTOCOLS BETWEEN THE BAY OF STRAW AND THE SADAO IN THE RIVER RIVER OF \\ THE PARAGUAY RIVER
}

\author{
José Lourenço Alves da Silva ${ }^{1}$, Célia Alves de Souza ${ }^{1}$ \\ 1 Universidade do Estado de Mato Grosso (UNEMAT), Cáceres, MT, Brasil
}

Correspondência para: José Lourenço Alves da Silva (Jose.geo.alves@hotmail.com)

doi: 10.12957/geouerj.2019.35448

Recebido em: 27 jun. 2018 | Aceito em: 27 ago. 2019

\section{RESUMO}

O rio Paraguai é um dos principais agentes modeladores do ambiente pantaneiro, suas mudanças hidromorfológicas estão vinculadas ao seu regime hídrico sua dinâmica fluvial e atividades antrópicas. O presente estudo objetivou avaliar os aspectos hidrossedimentológicos e o nível de degradação ambiental a partir de aplicação dos protocolos de avaliação rápida de rios - Pars, entre a Baía da Palha e o Sadao no corredor fluvial rio Paraguai. Para o desenvolvimento da pesquisa utilizou se algumas etapas. Trabalho de gabinete, trabalho de campo e de laboratório. Na etapa gabinete, foram realizadas pesquisas bibliográficas, perfis transversais e organização dos dados, no trabalho de campo, observação; aplicação de protocolos de avaliação rápida de rios; batimetria e velocidade do fluxo, coleta de amostras de água e sedimentos. Na análise laboratorial, foram realizadas análises: granulométrica (dispersão total e método de peneiramento), método de evaporação (concentração de sedimentos). Os Protocolos de Avaliação Rápida indicaram situações regulares para a margem esquerda das seções 1 e 5 . Nas seções transversais no rio Paraguai, a velocidade do fluxo variou entre 0,30 a 0,71 $\mathrm{m} / \mathrm{s}$, a profundidade média da lâmina de água entre 3,5 a 8,16 m, a vazão ficou entre 141,90 a 865,57 m³/s, a descarga sólida variou 245,20 a 1.496, t/dia. Nas seções localizadas na baía da Palha a velocidade do fluxo variou entre 0,09 a 0,97 m/s, a profundidade média da lâmina de água entre 0,46 a 7,06 m, a vazão ficou entre 0,29 a $673,95 \mathrm{~m}^{3} / \mathrm{s}$, e a descarga sólida variou de 53,74 a 2.329,17 t/dia. O uso antrópico influenciou diretamente em alterações na área de estudo em questão, porém a dinâmica de mudanças do rio Paraguai ocorre de forma natural desconfigurando suas feições através de deposições sedimentológicas.

Palavras-chave: Interferências Antrópicas. Dinâmica Fluvial. Morfologia de Canais

\begin{abstract}
The Paraguay River is one of the main modeling agents of the Pantanal environment, its hydromorphological changes are linked to its water regime its river dynamics and anthropic activities. The present study aimed to evaluate the hydrosedimentological aspects and the level of environmental degradation from the application of protocols for the rapid evaluation of rivers - Pars, between the Bay of Palha and Sadao in the river corridor Paraguay. For the development of the research was used some steps. Office work, fieldwork and laboratory work. At the cabinet stage, bibliographical research, cross-sectional profiles and data organization were carried out in the field work, observation; implementation of rapid river assessment protocols; bathymetry and flow velocity, water and sediment sample collection. In the laboratory analysis Analyzes were carried out: granulometric (total dispersion and sieving method), evaporation method (sediment concentration). The Rapid Assessment Protocols indicated regular situations for the left margin of sections 1 and 5. In the cross sections on the Paraguay River, flow velocity ranged from 0.30 to $0.71 \mathrm{~m} / \mathrm{s}$, the mean depth of the water sheet between 3.5 to $8.16 \mathrm{~m}$, the flow rate was between 141.90 to $865.57 \mathrm{~m}^{3} / \mathrm{s}$, the solid discharge varied from 245.20 to 1496 , $t /$ day. In the sections located in Palha bay flow velocity ranged from 0.09 to $0.97 \mathrm{~m} / \mathrm{s}$, the mean depth of the water slide was between 0.46 and $7.06 \mathrm{~m}$, the flow rate was between 0.29 and $673,95 \mathrm{~m}^{3} / \mathrm{s}$, and the solid discharge ranged from
\end{abstract}


53.74 to 2.329, 17 t / day. The anthropic use directly influenced changes in the study area in question, but the dynamics of changes in the Paraguay River occur naturally disfiguring their features through sedimentological depositions.

Keywords: Anthropic Interferences. River Dynamics. Channel Morphology.

\section{INTRODUÇÃO}

O rio Paraguai é um dos mais importantes do Brasil, “o rio principal e seus afluentes percorrem grandes extensões em planícies e pantanais mato-grossenses, contribuindo para a manutenção das características locais do Pantanal" (SOUZA, 2004 p. 6). Especificamente onde se encontra a referida área de estudo entre a Baía da Palha e o Sadao, além de água, recebe e transportam sedimentos e nutrientes do corredor fluvial do rio Paraguai abastecendo diversas outras feições como, baías, canais secundários, lagoas.

As baías são feições encontradas ao longo do perfil longitudinal de um rio, sendo considerada ambientes propícios a sedimentação, devido à redução do volume de água no período de estiagem. Segundo Souza (2004), as baías são áreas deprimidas de formas semicirculares e/ou irregulares sujeitas a impactos, principalmente em áreas urbanas e são amplamente encontradas no rio Paraguai.

Dessa forma, o rio Paraguai por possuir padrão meandrante, apresenta um processo intenso de erosão na margem côncava e deposição na margem convexa e na planície de inundação (SOUZA, 2004, p. 9). Ou seja, a morfologia dos canais, é alterada pela ação hidráulica das águas correntes. Para Christofoletti (1981), na dinâmica fluvial de canais meandrantes após os sedimentos serem retirados pela erosão, é depositado exatamente, no mesmo lado da mesma margem a jusante, formando diferentes feições ao longo da planície de inundação.

Estudos relacionados à morfologia de canais são indispensáveis para planejamento de bacias hidrográficas, principalmente em áreas urbanas; o alargamento dos canais é resultante da erosão e deposição. Na medida em que esse processo se intensifica, ocorrem as formas deposicionais de fundo, bancos de confluência, soleira, e depressões, podendo ser inevitável o surgimento de inúmeros problemas principalmente em áreas urbanas e/ou ribeirinhas (CUNHA, 2008). 
Mudanças na morfologia de canais ocorrem de forma natural ou a partir de impactos relacionados a atividades humanas. Ainda segundo Cunha (2008), compreende um papel fundamental para a morfologia fluvial, trabalhar com a natureza e não contra ela, contribuindo para gestão das bacias hidrográficas e para qualidade de vida das pessoas.

Entretanto Silva (2012) enfatiza que o processo de erosão fluvial e sedimentação em rios também ocorrem de forma natural, independentemente da presença do homem, tais processos erosivos na margem dos rios só passam a ser um problema para a sociedade quando o homem ocupa, de modo inadequado estas áreas, acelerando ou barrando a ação erosiva.

Nos últimos anos, estudiosos vêm discutindo acerca da dinâmica fluvial dos rios, por possuir grande relevância para os estudos de geomorfologia fluvial e hidráulica. Silva et al. (2012) descreveram que os dados obtidos (batimetria, granulometria dos sedimentos e vazão) auxiliam na compreensão dos elementos que envolvem a rede de drenagem, a fim de elucidar questões relacionadas aos problemas ambientais existentes como a erosão e sedimentação.

Para Suguio e Bigarela (1990) o processo de sedimentação fluvial não pode ser analisado de forma isolada, porque ocorre principalmente através dos processos da corrosão, corrasão e cavitação. Os autores ainda salientam que os estudos relacionados à dinâmica fluvial possuem grande importância para a geomorfologia fluvial e hidráulica.

Assim sendo, todo rio possui em sua dinâmica um equilíbrio entre a sua descarga, velocidade média, carga sedimentar e a fisionomia de seu leito. Todos esses elementos envolvidos formam a geometria hidráulica de um rio. Uma vez alterados, promovem a desestabilização de todo sistema fluvial, a consequência dessa atividade é o abandono de canais, geração e destruição de ilhas e migração de canais. (LEOPOLD e MADDOCK, 1953; ROCHA, 2011).

Associados ao crescimento urbano, rios têm sofrido transformações, perdendo suas características naturais. Para Christofoletti (1977), as atividades humanas podem aumentar ou diminuir a quantidade 
de água escoada superficialmente, tendo consequências no regime fluvial e na intensidade das cheias.

Para se controlar os problemas ligados à sedimentação, é preciso agir na rede dos canais de escoamento e no fluxo das águas sobre as vertentes.

Portanto, ações antrópicas estão influenciando nos fatores condicionantes hidrológicos, morfológicos, de forma impactante na área que corresponde entre a Baía da Palha e o Sadao no corredor fluvial do rio Paraguai. Dessa forma o presente estudo teve por objetivo avaliar os aspectos hidrossedimentológicos e níveis de degradação ambiental a partir de aplicação dos protocolos de avaliação rápida de rios - Pars, entre a Baía da Palha e o Sadao no corredor fluvial rio Paraguai.

\section{MATERIAL E MÉTODO}

\section{Área de estudo}

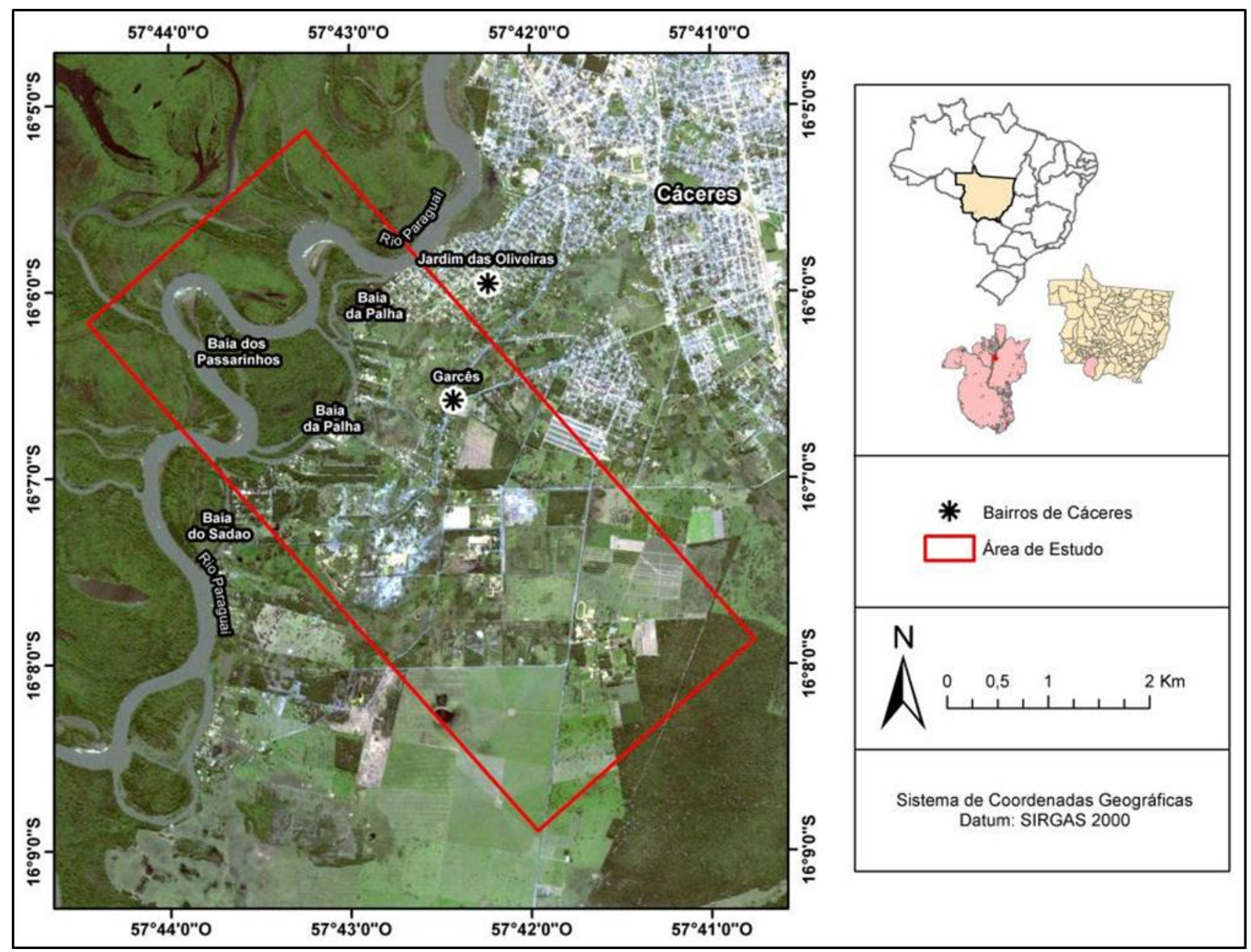

Figura 1. Localização geográfica do trecho entre a Baía da Palha e a Baía do Sadao. Fonte: Autor 
A Bacia Hidrográfica do rio Paraguai é constituída por diversos depósitos sedimentares pertencentes ao grupo Alto Paraguai, sendo composta pelas formações, Araras, Raizama, Sepotuba e Pantanal, localizadas no limite do cráton sul amazônico.

\section{Procedimentos Metodológicos}

O presente trabalho foi realizado em um período de monitoramento de dois anos, através das seguintes etapas: Trabalho de gabinete, trabalho de campo e de laboratório. No trabalho de gabinete foi realizado pesquisa bibliográfica a partir de fontes seguras como: google acadêmico, Scielo entre outras, onde foi utilizado: livros, artigos, teses, dissertações elaboração de mapa de localização, perfis transversais, gráficos e tabelas.

Para confecção do mapa de localização utilizou o Sistema de Informações Geográfico (GIS / SIG) pelo software ArcGis 9.3, licenciado, sendo interpretado e projetado o mapa sobre a escala de 1: 20.000.

A área e o perímetro foram calculados pelo para obter índice de vazão utilizou a seguinte fórmula: $\mathrm{Q}=$ V x A (Cunha, 2009). Onde: $\mathrm{Q}=$ Vazão; $\mathrm{V}=$ velocidade da água; $\mathrm{A}=$ Área. No trabalho de campo foi realizado no período de início de cheia, cheia e seca, foram escolhidas nove seções transversais, quatro no rio Paraguai, quatro na baía da Palha e uma na baía dos Passarinhos.

Os perfis transversais foram elaborados em forma de croquis, confeccionados primeiramente pela compilação dos dados obtidos em campo através das medidas de profundidade e largura dos canais. Para maior precisão dos dados e comparação das informações, utilizou-se a confecção manual em papel milimetrado, por meio de uma única escala para todas as seções. Sendo utilizada a medida para escala vertical $1 \mathrm{~cm}=1 \mathrm{~m}$; e para a escala horizontal $0,05 \mathrm{~cm}=1 \mathrm{~m}$. Por fim, utilizou-se o software Corel Draw X4 para a confecção do produto de cada seção transversal.

No trabalho de campo foi realizado as seguintes atividades: Batimetria (largura e profundidade), Em cada seção transversal foi verificada a velocidade a partir de três setores: margem esquerda, direita e 
centro do canal. Respectivamente, foram medidas três velocidades em profundidades distintas a $20 \%$, $50 \%$ e $80 \%$ do total da profundidade local em todos os pontos, foi utilizando o sonar Garmin GPSMAP420S e o molinete fluviométrico MLN 7.

Na coleta de sedimentos de fundo utilizou o mostrador Van Veen e para coletar a carga de suspensão usou garrafa de Van Dorn e por fim, houve aplicação do protocolo de avaliação rápida de rios.

Por definição, para aferir a qualidade ambiental, foram utilizados os Protocolos de Avaliação Rápida de Rios (PARs), cabe ressaltar que foi aplicado um protocolo em cada margem (margem e direita). Os PARs são documentos de referência que agregam procedimentos metodológicos aplicáveis à avaliação rápida, fatores geomórficos (erosão) e sedimentológicos (deposição) que condicionam e controlam os processos e funções dos sistemas fluviais. As pontuações finais refletiram no nível de preservação das condições ecológicas, morfológicas e hidrológicas dos trechos da área estudada.

O PAR proposto por Rodrigues et al. (2012) avalia parâmetros morfológicos: deposição de sedimentos, alterações no canal, estabilidade das margens, proteção das margens pela vegetação e estado de conservação da vegetação do entorno. Foram aferidas por uma pontuação que pode variar sendo classificadas como: 0 a 1 - Péssima; 1,1 a 2 - Regular e 2,1 a 3 - Boa.

No trabalho de laboratório para a determinação dos tipos de sedimentos foram utilizados os métodos de peneiramento e pipetagem "dispersão total" (EMBRAPA, 1997). Amostras (20 g) foram mantidas por 12 horas em contato com solução dispersante (NaOH 0,1M.L-1) as amostras foram agitadas mecanicamente durante 15 minutos no Agitador de Wagner TE-160 em garrafas de Stohlmann. A fração argila foi determinada pelo método da pipeta, que consiste em pipetar um volume da suspensão que foi seca em estufa. A fração areia foi separada por peneira.

Para determinação do tamanho das partículas das amostras de sedimentos de fundo foi adotado o método de peneiramento. As amostras coletadas foram secas em estufa a $120^{\circ} \mathrm{C}$. O material seco foi agitado mecanicamente no decímetro, que é um aparelho com uma sequência de peneiras padronizadas. A 
amostra de cada ponto foi agitada por 30 minutos. Posteriormente, o material retido em cada uma das peneiras foi pesado separadamente quando se determinaram as frações Areia Grossa, Areia Média e Areia Fina (SUGUIO, 1973).

Para aferir a quantidade de sedimentos em suspensão foi realizado o (Método de evaporação) onde foram inseridas em recipiente adequado para evaporação (béqueres de $1000 \mathrm{ml}$ ) e levadas à estufa a $105{ }^{\circ} \mathrm{C}$ para secagem, a diferença do peso é a carga suspensa (CARVALHO et al., 2000).

Os valores de descarga sólida em suspensão (QSS) foram determinados pelo somatório do produto entre a concentração de sedimento suspenso da vertical (CSSi) e a respectiva descarga líquida da vertical (Ql), na forma da expressão abaixo:

$$
Q_{S S} \equiv \sum\left(C_{S S_{i}} \cdot Q l_{i}\right) \cdot 0,0864
$$

Em que: Qss = descarga sólida em suspensão (t/dia-1); Cssi = concentração de sedimento em suspensão da vertical (mg/l-1); Qli = descarga líquida da respectiva vertical (m3/ s-1).

\section{RESULTADOS E DISCUSSÃO}

Os dados sobre os protocolos de avaliação rápida e hidrodinâmica foram obtidos em nove seções transversais. As seções 1, 3, 4 e 8 encontram-se no rio Paraguai; as seções 2, 5, 6 e 7 localizam-se na Baía da Palha; a seção 9, na Baía dos Passarinhos.

De acordo com o gráfico dos protocolos de avaliação rápida aplicados no trecho entre o furado da Palha e a Baía do Sadao a seção 01 e 05, à margem esquerda, alcançou situação regula, a seção 09 foi o trecho que apresentou melhor situação em nível de alterações. (Figura 2). 


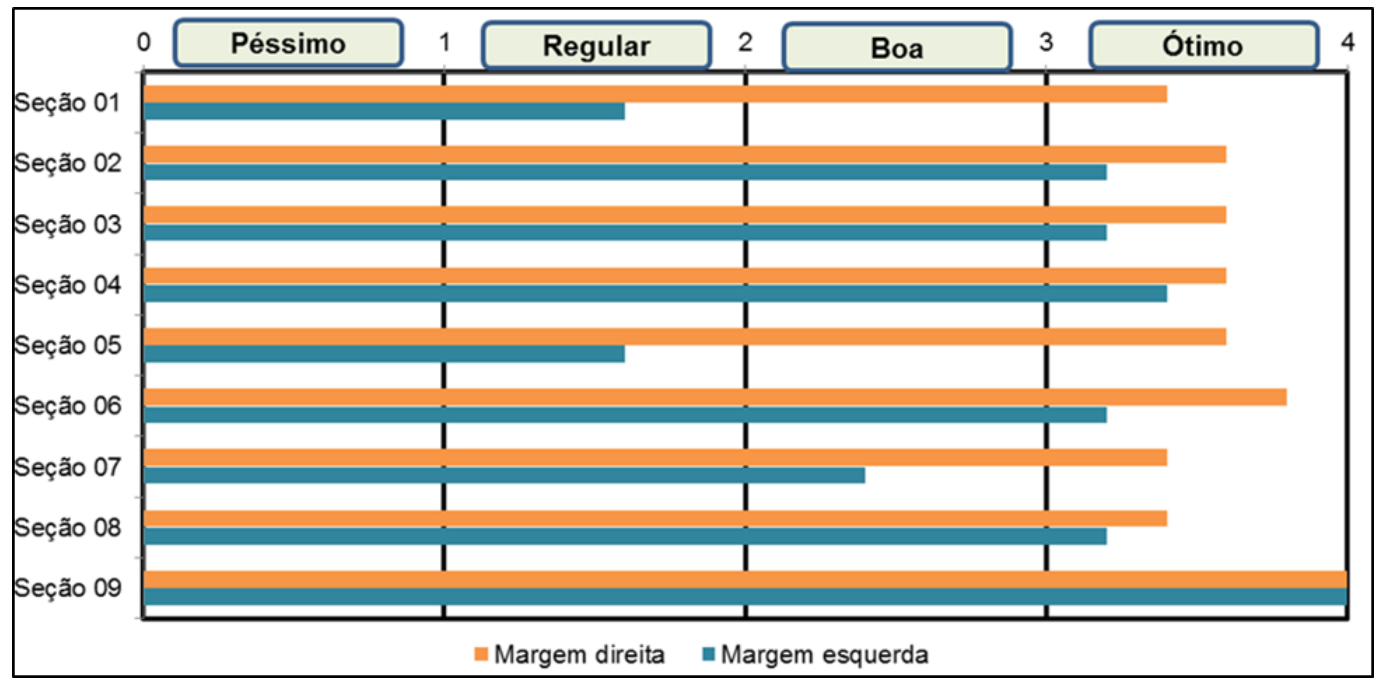

Figura 2. Níveis de degradação dos pontos amostrais, através dos parâmetros dos Protocolos de Avaliação Rápida. Fonte: Autor.

Com a aplicação do Protocolo de Avaliação Rápida de Rios (PARs), em nove seções, mostraram-se os níveis de degradação dos pontos amostrais. Os tipos de ocupação evidenciados foram: residencial e residencial misto, além da área destinada para fins industriais.

a) Seção 01

A seção 01 encontra-se no rio Paraguai a montante da entrada baía da Palha. 0 canal principal apresenta padrão meandrante, com intensa erosão na margem esquerda côncava e deposição em margem direita convexa (Figura 3).

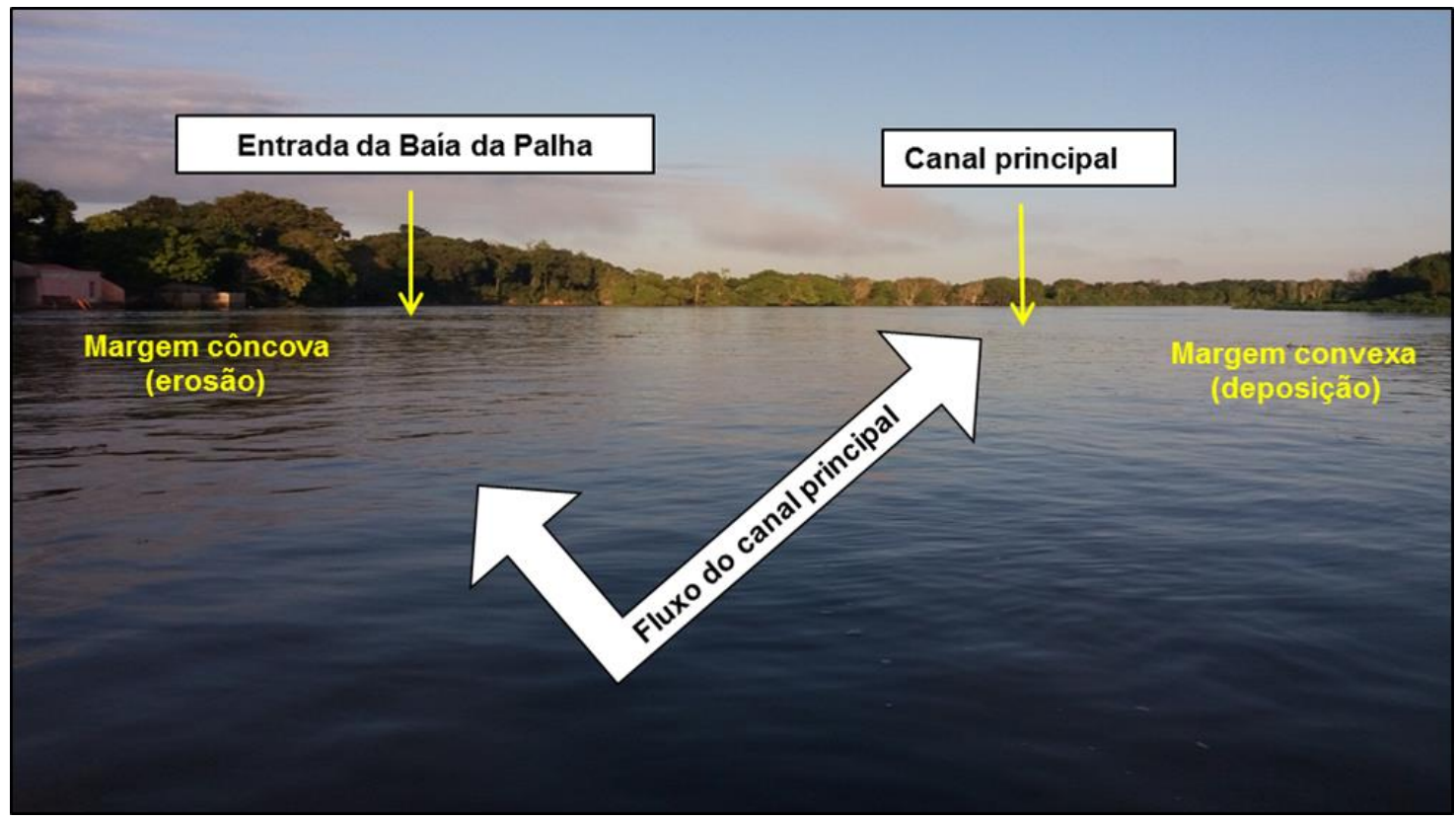

Figura 3. Seção monitorada 01 no canal principal e na entrada da Baía da Palha. Fonte: Autor. 
A margem esquerda da área encontra-se antropizada pela urbanização, com a presença de casas de veraneio e residências. $\mathrm{O}$ canal nesse ponto a montante está sendo explorado por dragagem para retirada de areia. De acordo com os resultados do protocolo, constatou-se uma situação regular.

Cabe salientar a solução encontrada na margem esquerda pela maioria dos moradores promovem o uso de revestimento com cimento nas paredes das edificações para contenção da erosão, que é alta no período de cheia. A vegetação ao entorno foi praticamente toda retirada pela urbanização, sendo quase inexistente.

A margem esquerda apresentou situação regular por ter sido modificada pela ação antrópica. A vegetação ciliar foi totalmente retirada, sendo substituídas por construção de residências, casas de veraneio e instalações de uma areeira. No trecho entre a Baía da Palha e a Baía do Sadao, a solução para contenção das erosões são os muros de arrimo.

A retirada da vegetação na margem esquerda implicou na instabilidade das margens, acelerando os processos erosivos marginais e influenciando também na dinâmica fluvial, no aumento do escoamento superficial e em maior transporte de sedimentos, colaborando para assoreamentos a jusante.

As ações antrópicas nessa seção também refletiram para obtenção de índices elevados nas variáveis hidrodinâmicas nos três períodos de monitoramento. Dessa forma, no mês de dezembro de 2017, o canal apresentou uma largura de $145 \mathrm{~m}$, com profundidade média de $6,2 \mathrm{~m}$; a área da seção transversal era de $899,00 \mathrm{~m}^{2}$; a velocidade média no fluxo foi de $0,45 \mathrm{~m} / \mathrm{s}$ e a vazão registrada foi de $404,55 \mathrm{~m}^{3} / \mathrm{s}$ (Tabela 1). A concentração de material suspenso foi de $20 \mathrm{mg} / \mathrm{l}$ e a descarga sólida suspensa atingiu 699,06 t/dia.

\begin{tabular}{cccccccc}
\hline Campo & $\begin{array}{c}\text { Velocidade } \\
\text { Média m/s }\end{array}$ & $\begin{array}{c}\text { Profundidade } \\
\text { Média }\end{array}$ & $\begin{array}{c}\text { Largura } \\
\mathbf{( M e t r o s )}\end{array}$ & $\begin{array}{c}\text { Área da } \\
\text { Seção } \\
\left(\mathbf{M}^{\mathbf{2}}\right)\end{array}$ & $\begin{array}{c}\text { Vazão } \\
\left(\mathbf{M}^{\mathbf{3}} / \mathbf{s}\right)\end{array}$ & $\begin{array}{c}\text { Suspensão } \\
\mathbf{( m g / L )}\end{array}$ & $\begin{array}{l}\text { Descarga } \\
\text { Sólida } \\
\mathbf{( t / d i a )}\end{array}$ \\
\hline $\mathbf{1}$ & 0,45 & 6,2 & 145,00 & 898,38 & 404,55 & 20 & 698,57 \\
$\mathbf{2}$ & 0,71 & 8,16 & 149,45 & 1219,51 & 865,85 & 20 & 1496,19 \\
$\mathbf{3}$ & 0,33 & 5,10 & 135,00 & 698,70 & 230,57 & 40 & 796,84 \\
\hline
\end{tabular}

Tabela 1. Variáveis Hidrodinâmicas Seção 01. Fonte: Autor. 
A margem direita demonstrou-se estável, apresentando situação ótima, com ausência mínima de erosão. Ao traçar-se o perfil transversal a jusante da estrutura da draga que explora o leito, ficou evidente que a morfologia da calha apresenta uma dinâmica de canal meandrante (Figura 4), ou seja, a deposição de sedimentos ocorre na margem convexa. Além disso, houve o processo de formação de uma barra lateral a jusante.

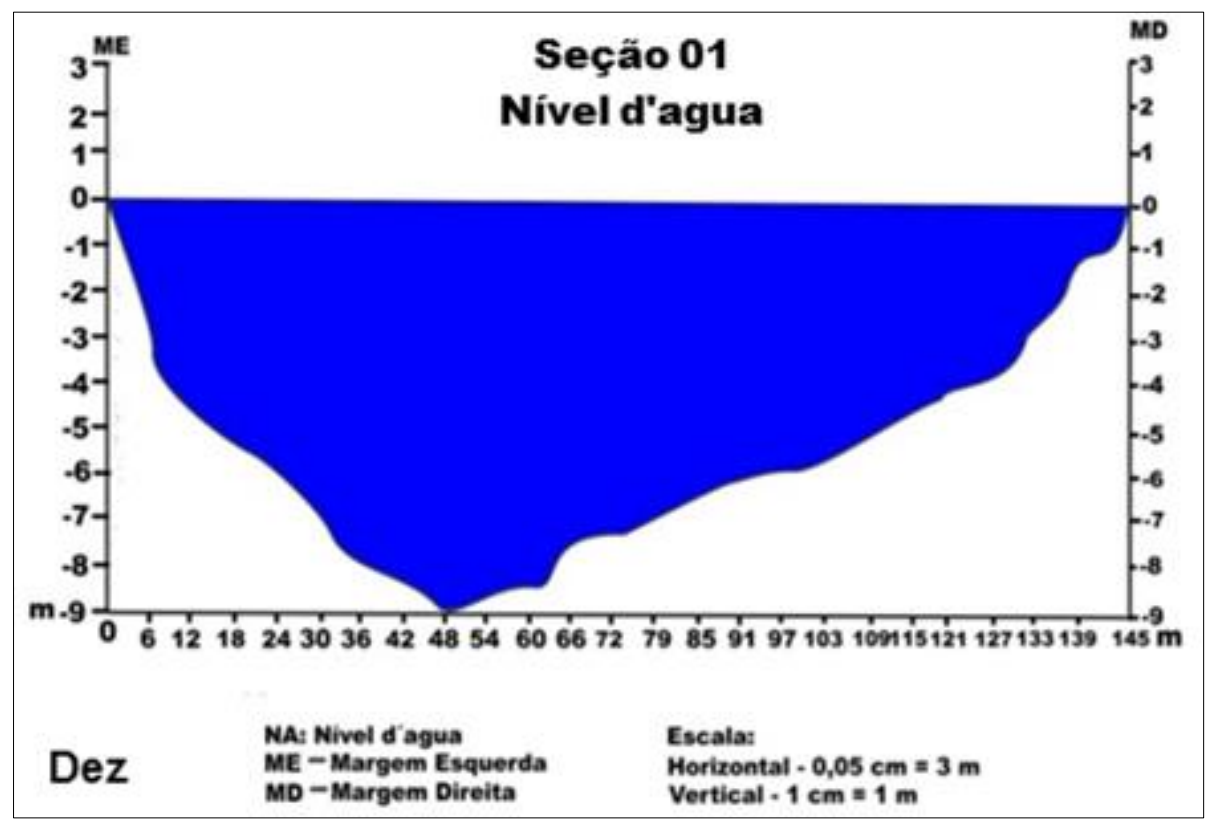

Figura 4. Perfil transversal no canal principal no rio Paraguai. Fonte: Autor.

Na margem direita, ainda foi evidenciado que mais de $90 \%$ da superfície é coberta por vegetações nativas. A maioria das plantas pode crescer naturalmente. No entorno, a vegetação ainda é composta por espécies nativas remanescentes, arbórea e herbácea em bom estado de conservação, não apresentando sinais de degradação causada por atividades humanas, como pastagens e/ou áreas de cultivos.

No período chuvoso, em fevereiro de 2017, o canal apresentou aumento na largura da lâmina d' agua 149,45m; a profundidade média atingiu de 8,16 m, estabelecendo uma velocidade média em seu fluxo de $0,71 \mathrm{~m} / \mathrm{s}$ e a vazão de $865.85 \mathrm{~m}^{3} / \mathrm{s}$. Na medida em que a vazão (descarga liquida) aumentou, a descarga sólida também cresceu, alcançando 1496,19 t/dia. A concentração de sedimentos suspensos atingiu $20 \mathrm{mg} / \mathrm{l}$. 
O aumento da carga de sedimentos finos está associado à remobilização de sedimentos pelas dragas a montante, onde o leito é explorado pela areeira. Dessa forma, a granulometria de sedimentos de fundo nos três períodos de monitoramento evidenciou predominância de areia fina: 93,40\%em dezembro de 2017, 71,30\% em fevereiro e 93,80\% agosto de 2017 (Figura 5).

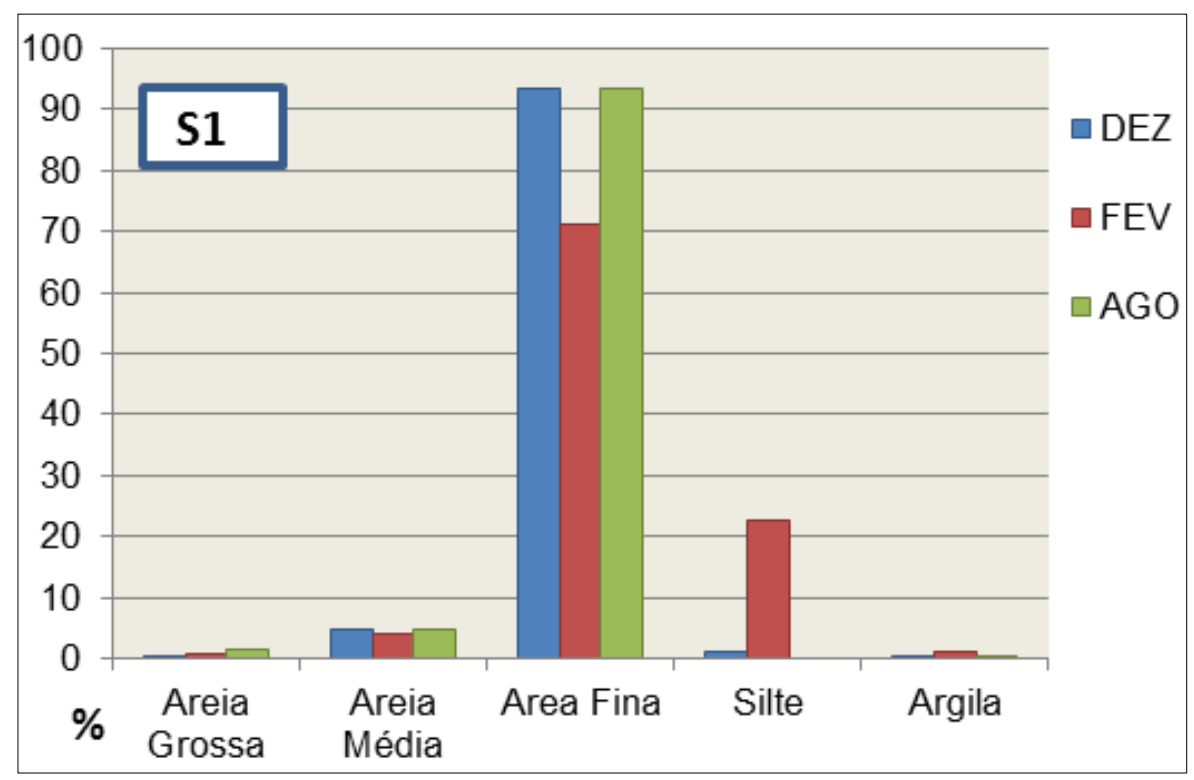

Figura 5. Perfil transversal no canal principal no rio Paraguai. Fonte: Autor.

No período de estiagem, em agosto de 2017 , os valores diminuíram em relação ao período de cheia, a largura da seção transversal foi de 137,00m. A profundidade média no nível da água foi de 5,1m em uma área de seção com $698,70 \mathrm{~m}^{2}$; a velocidade média do fluxo de 0,45 e a vazão $230,57 \mathrm{~m}^{3} / \mathrm{s}$; a concentração de material suspenso atingiu 40 mg/l e a descarga sólida alcançou 796,84 t/dia.

b) Seção 02

Essa seção está localizada na Baía da Palha, na parte superior, apresentou ótima situação em ambas as margens considerando a aplicação dos protocolos, porem, a montante o referido canal, recebe poluição e sedimentos do córrego do Junco, que deságua na entrada do canal. A vegetação na margem esquerda apresentou está em boas condições, está relacionada à área de preservação permanente (mata ciliar), sendo composta pela vegetação nativa, não apresentando sinais de degradação. 
Em dezembro, a margem apresentou-se estável, com ausência mínima de erosão, com pouco potencial para problemas futuros. A largura de do canal apresentou 41,00 m, a profundidade média foi de 5,23 m, a área da seção transversal foi de $214,32 \mathrm{~m}^{2}$, a velocidade média do fluxo foi de $0,51 \mathrm{~m} / \mathrm{s}$ e a vazão de $109,30 \mathrm{~m}^{3} / \mathrm{s}$. A margem direita apresentou-se moderadamente estável, cicatrizada ao longo da seção (Tabela 2).

\begin{tabular}{cccccccc}
\hline \multirow{2}{*}{ Campo } & $\begin{array}{c}\text { Velocidade } \\
\text { Média m/s }\end{array}$ & $\begin{array}{c}\text { Profundidade } \\
\text { Média }\end{array}$ & $\begin{array}{c}\text { Largura } \\
(\text { Metros) }\end{array}$ & $\begin{array}{c}\text { Área } \\
\mathbf{d a} \\
\text { Seção } \\
\left(\mathbf{M}^{\mathbf{2}}\right)\end{array}$ & $\begin{array}{c}\text { Vazão } \\
\left(\mathbf{M}^{\mathbf{3}} / \mathbf{s}\right)\end{array}$ & $\begin{array}{c}\text { Suspensão } \\
(\mathbf{m g} / \mathbf{L})\end{array}$ & $\begin{array}{c}\text { Descarg } \\
\text { a Sólida } \\
\text { (t/dia) }\end{array}$ \\
\hline $\mathbf{1}$ & 0,51 & 5,23 & 41,00 & 214,32 & 109,30 & 20 & 188,87 \\
$\mathbf{2}$ & 0,45 & 5,33 & 49,65 & 264,63 & 119,09 & 20 & 205,78 \\
$\mathbf{3}$ & 0,45 & 3,30 & 39,00 & 128,70 & 57,91 & 20 & 100,06 \\
\hline
\end{tabular}

Tabela 2. Variáveis Hidrodinâmica Seção 02. Fonte: Autor.

Esse canal está em processo de evolução. A morfologia da calha apresentou um formato em "V", indicando um talvegue bem definido (Figura 6), o que justifica os elevados valores de velocidade do fluxo nos três períodos de monitoramento devido ao formato da calha.

A vegetação na margem direita apresentou-se com mínimas evidências de impactos causados pela atividade humana, mantendo-se bem preservada. A baixa interferência antrópica influenciou para a baixa concentração do material suspenso, que foi de $20 \mathrm{mg} / \mathrm{l}$, a carga sólida suspensa foi de 188,87 t/dia.

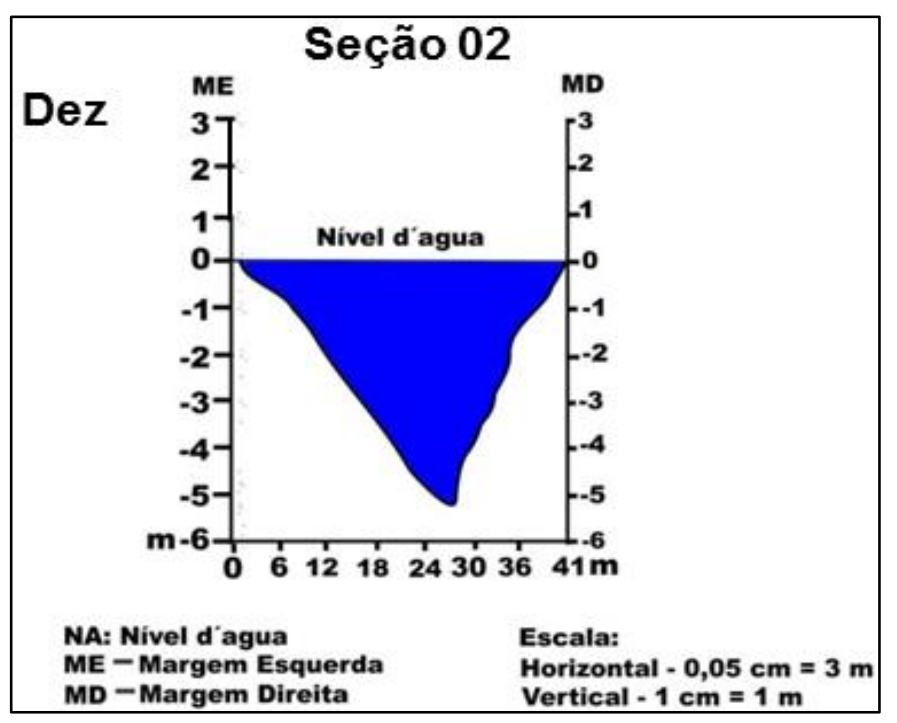

Figura 6. Perfil transversal no canal da Baía da Palha.Fonte: Autor. 
Diante disso, em fevereiro, a profundidade média aumentou: foi de 5,23m para 5,33m; a largura do canal foi 49,65m, com área da seção transversal de 264,63 m². A velocidade média do fluxo foi de 0,45 m/s, com vazão de $119,09 \mathrm{~m}^{3} / \mathrm{s}$. A concentração de sedimentos suspenso foi de $20 \mathrm{~m} / \mathrm{l}$, e a carga suspensa atingiu $205,78 \mathrm{t} /$ dia.

Cabe destacar que, nessa seção, houve aprofundamento da calha para facilitar na navegação, o que influenciou para aumento da velocidade do fluxo. Concomitantemente, houve o aumento de carga de sedimentos finos transportados e depositados no interior do canal, além do córrego do junco, que também contribui para transportar sedimentos para essa seção, onde nos três períodos houve deposições de materiais finos no leito, as análises granulométricas evidenciaram que em dezembro de 2016 a porcentagem foi de $54,4 \%$ de areia fina, $95,05 \%$ em fevereiro de 2017 e em agosto foi de 58,10\% (Figura 7).

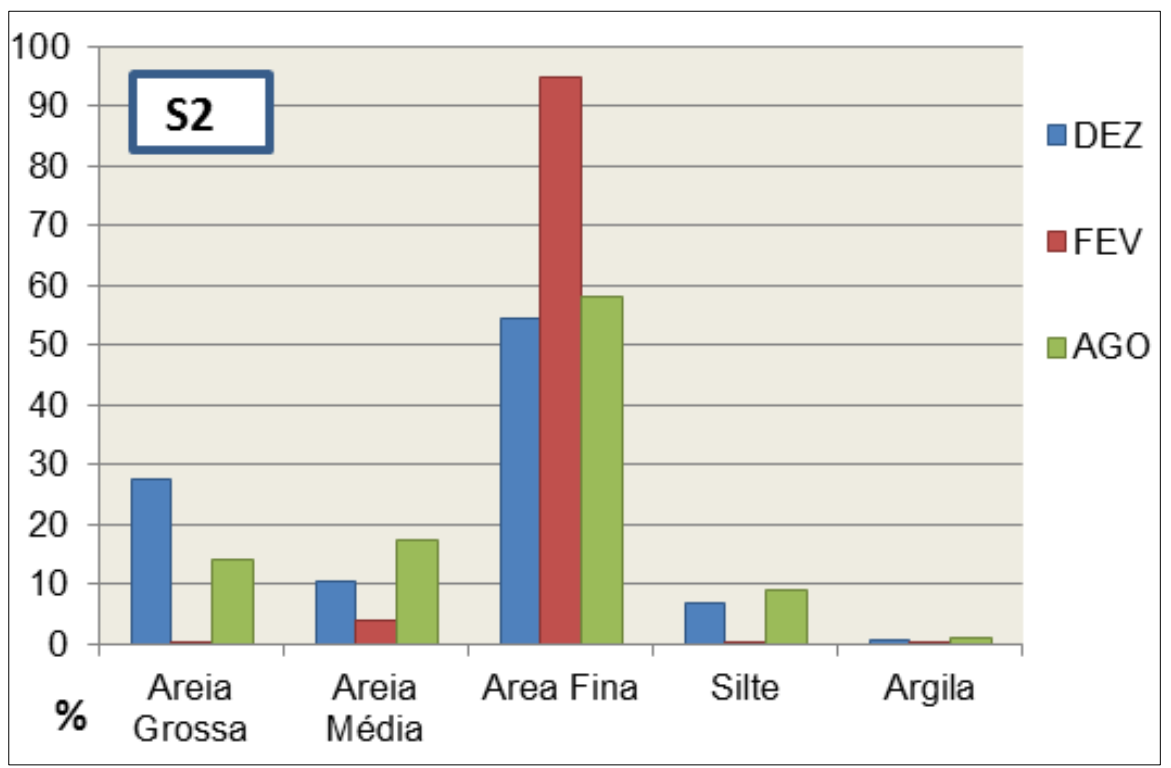

Figura 7. Porcentagens da granulometria de sedimentos de fundo. Fonte: Autor.

O fato de o canal sofrer com interferências em seu leito justificou-se ao ser constatado que, na margem esquerda, havia trilhas abertas por pescadores ribeirinhos, que utilizam a área para pesca e ancoradouro de pequenas embarcações e pela proximidade da área com o perímetro urbano, por conta das proximidades com os bairros ao entorno Jardim das Oliveiras. Contudo, a margem apresentou-se estável, com ausência mínima de erosão e com pouco potencial para problemas futuros. 
No mês de agosto de 2017, os valores hidrodinâmicos obtiveram diferenças em relação aos valores dos meses anteriores, por estar no período de estiagem, demonstrando que o canal mantém sua dinâmica permanente. A profundidade média diminuiu e apresentou $3,30 \mathrm{~m}$, a largura do canal foi de $39 \mathrm{~m}$ e a área de seção foi de $128,70 \mathrm{~m}^{2}$. A velocidade do fluxo foi de $0,45 \mathrm{~m} / \mathrm{s}$ e a vazão mensurada foi de 57,91 $\mathrm{m}^{3} / \mathrm{s}$. A concentração do material suspenso foi de $20 \mathrm{mg} / \mathrm{l}$ e a descarga sólida alcançou 100,06 t/dia.

c) Seção 03

Observou-se, nessa seção que, no canal principal do rio Paraguai, houve a ausência mínima de canalizações e dragagens ou qualquer outra forma de interferência que pudesse afetar o curso d'água, seguindo como padrão natural. Diante disso, no período chuvoso, em dezembro de 2016, a profundidade média apresentou 5,05 m e a largura do canal foi de $166,58 \mathrm{~m}$, obtendo a seção transversal de 841,22 $\mathrm{m}^{2}$. A velocidade média do fluxo foi de $0,45 \mathrm{~m} / \mathrm{s}$ e a vazão atingiu $356,78 \mathrm{~m}^{3} / \mathrm{s}$. A concentração de material em suspensão alcançou $40 \mathrm{mg} / \mathrm{l}$, logo a descarga sólida foi de 554,86 t/dia (Tabela 3).

\begin{tabular}{|c|c|c|c|c|c|c|c|}
\hline Campo & $\begin{array}{l}\text { Velocidade } \\
\text { Média m/s }\end{array}$ & $\begin{array}{c}\text { Profundidade } \\
\text { Média }\end{array}$ & $\begin{array}{l}\text { Largura } \\
\text { (Metros) }\end{array}$ & $\begin{array}{c}\text { Área da } \\
\text { Seção } \\
\left(M^{2}\right)\end{array}$ & $\begin{array}{l}\text { Vazão } \\
\left(M^{3} / \mathbf{s}\right)\end{array}$ & $\begin{array}{c}\text { Suspensão } \\
(\mathrm{mg} / \mathrm{L})\end{array}$ & $\begin{array}{c}\text { Descarga } \\
\text { Sólida } \\
\text { (t/dia) }\end{array}$ \\
\hline 1 & 0,45 & 5,05 & 166,58 & 841,22 & 356,78 & 40 & 554,86 \\
\hline 2 & 0,56 & 6,0 & 171,64 & 1029,84 & 576,71 & 20 & 996,56 \\
\hline 3 & 0,30 & 3,50 & 155,00 & 542,50 & 162,75 & 20 & 281,23 \\
\hline
\end{tabular}

Tabela 3. Variáveis Hdrodinâmicas seção 03. Fonte: Autor.

A margem direita apresentou-se moderadamente instável, com a presença de erosões e com potencial alto durante as cheias. Esses elementos justificaram o aumento do material suspenso no primeiro mês de monitoramento que, em dezembro, início do período de cheia, foi de $(40 \mathrm{mg} / \mathrm{l})$, não apresentando deposição por ser margem de erosão (côncava).

No que diz respeito à proteção das margens, elas são cobertas por vegetação ribeirinha, as espécies desenvolvem-se naturalmente. Quanto à vegetação no entorno, possui espécies nativas em bom estado de conservação, não apresentando sinais de degradação causada por atividades humanas. 
Na margem direita, houve acréscimos de sedimentos finos, formando uma barra lateral, pois a margem é de deposição. Uma extensa barra de sedimentos na margem convexa apresenta extensão de 10,75 metros de comprimento de barra lateral (Figura 8).

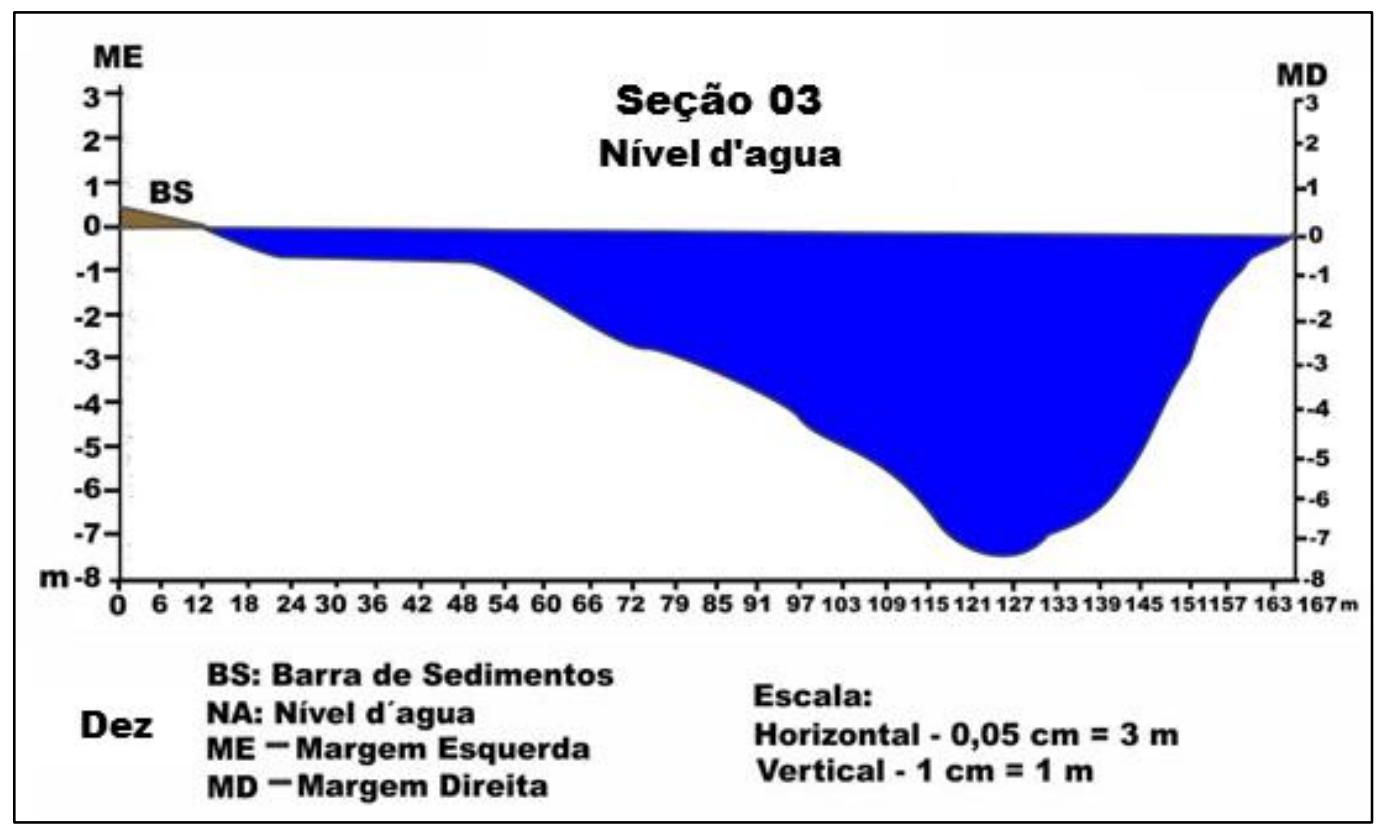

Figura 8. Porcentagens da granulometria de sedimentos de fundo. Fonte: Autor.

No mês de fevereiro 2017, a profundidade média no nível da água foi de 06 metros e a largura do canal foi de 171,64 metros, com a área da seção transversal de 1029,84m² . A velocidade média do fluxo foi de $0,56 \mathrm{~m} / \mathrm{s}$ e a vazão apresentou valor de $576,71 \mathrm{~m}^{3} / \mathrm{s}$. A concentração de material suspenso foi de 20mg/l e a descarga sólida de 996,56 t/dia.

Em relação à granulometria da carga de fundo do canal, houve a predominância de areia fina, atingindo uma média de $92,78 \%$ nos três períodos monitorados, relacionado à própria dinâmica de padrão meandrante que o rio Paraguai possui, tendência de transportar uma carga de materiais grosseiros areias: grossa, média e fina, como na maioria dos rios sinuosos de planícies. Os materiais mais finos são depositados na margem de baixa velocidade (convexa) e também no leito, formando feições como as barras e alterando a morfologia da calha. Os materiais mais grosseiros são arrancados e transportados pela alta velocidade fluxo do canal em margem côncava (Figura 9). 


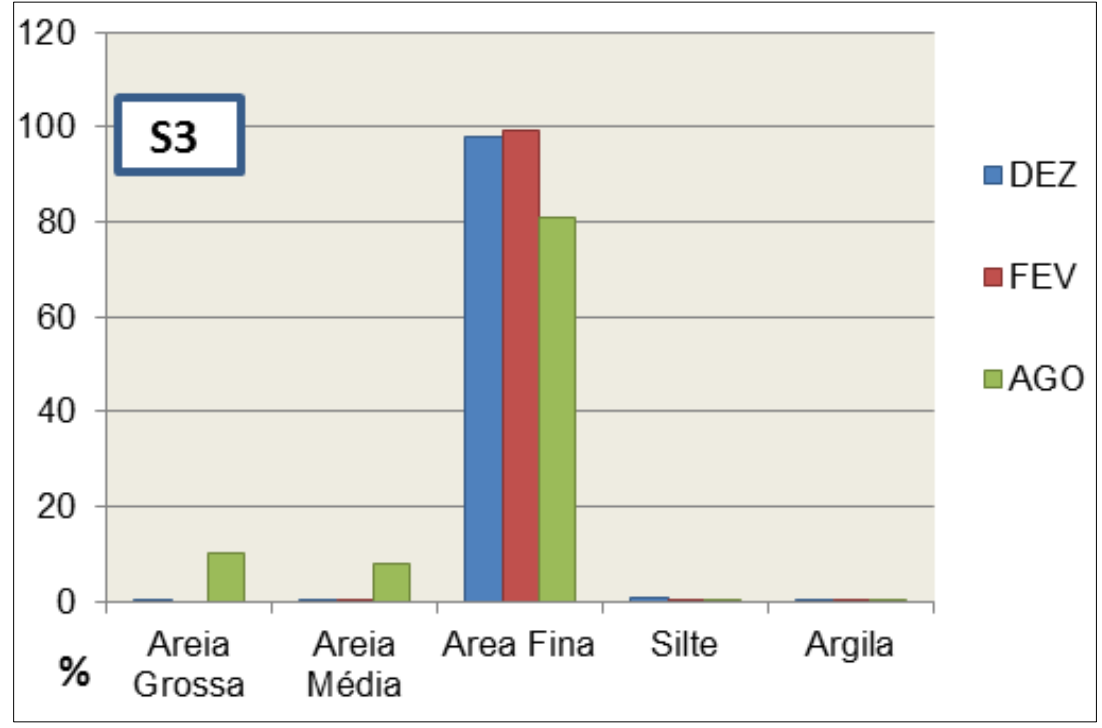

Figura 9. Porcentagens da granulometria de sedimentos de fundo. Fonte: Autor.

Dessa forma, em agosto de 2017, o canal apresentou uma velocidade média de $0,30 \mathrm{~m} / \mathrm{s}$, a largura da lâmina d'agua foi de 155 metros, mensurando uma área de seção com 542,50 m². A velocidade média do fluxo atingiu $0,30 \mathrm{~m} / \mathrm{s}$. A concentração de sedimentos suspensos obteve $20 \mathrm{mg} / \mathrm{l}$ e a carga suspensa atingiu 281,23 t/dia. A diminuição da lâmina d'água resultou no aumento da barra de sedimentos, que, em agosto de 2017, apresentou maior largura (36 metros) e 454,40 metros de extensão. Essas medidas estão relacionadas à diminuição da lâmina d'água em relação à altura da barra que chegou a apresentar 1,31 metros.

Nesta seção, as margens onde foram aplicados os protocolos apresentaram ótimas situações, no canal não houve a presença de nenhum tipo de canalização ou qualquer outra forma de interferência que afetou o curso d'água. Neste caso, o curso seguiu como natural. A morfologia da calha indica que o canal possui padrão meandrante (Figura 10). Na margem direita, houve acréscimos de sedimentos finos, formando uma barra lateral, pois a margem é de deposição.

Ainda na margem direita, nesse segmento, houve a presença de ocupações, notoriamente uma casa de apoio para pescadores ribeirinhos. Ao entorno, a vegetação natural apresentou-se em boas condições, estando bem conservada. 


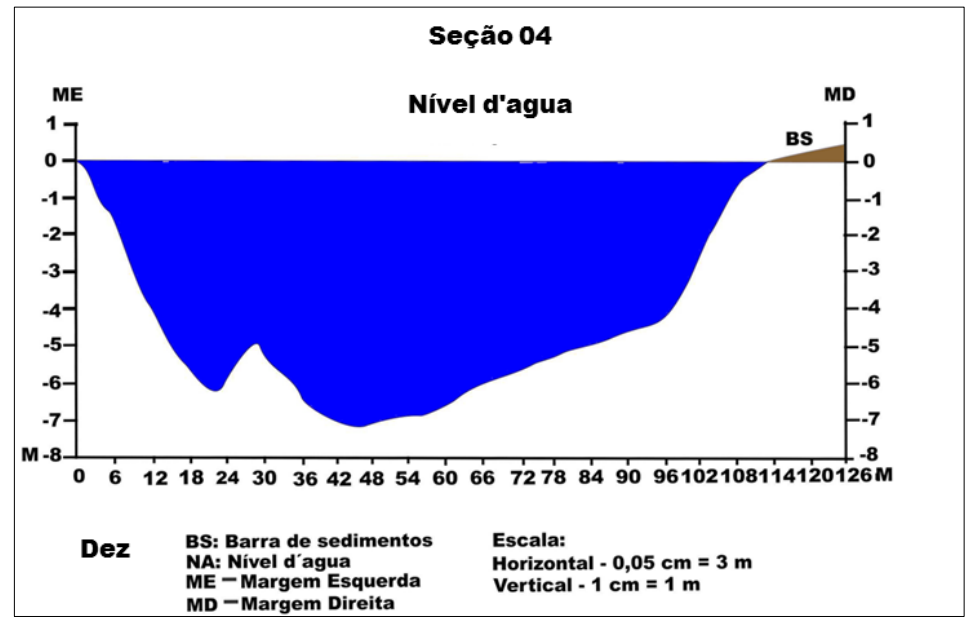

Figura 10. Perfil transversal no canal principal do rio Paraguai. Fonte: Autor.

Na margem esquerda da área, devido à alta velocidade exercida em margem convexa, ficaram evidenciadas erosões com grande potencial durante as cheias, apresentando-se instáveis.

Dessa maneira, no mês de dezembro, a largura do canal apresentou $119 \mathrm{~m}$ e profundidade média de 4,06m, com a área da seção transversal de $483,14 \mathrm{~m}^{2}$. A velocidade do fluxo foi de $0,30 \mathrm{~m} / \mathrm{s}$ e a vazão registrada foi de $202,91 \mathrm{~m}^{3} / \mathrm{s}$. A concentração de sólidos suspensos foi de $40 \mathrm{mg} / \mathrm{l}$ e a carga sólida suspensa foi de $701,25 \mathrm{t} /$ dia (Tabela 4 ).

\begin{tabular}{cccccccc}
\hline Campo & $\begin{array}{c}\text { Velocidade } \\
\text { Média m/s }\end{array}$ & $\begin{array}{c}\text { Profundidade } \\
\text { Média }\end{array}$ & $\begin{array}{c}\text { Largura } \\
(\text { Metros) }\end{array}$ & $\begin{array}{c}\text { Área da } \\
\text { Seção } \\
\left(\mathbf{M}^{2}\right)\end{array}$ & $\begin{array}{c}\text { Vazão } \\
\left(\mathbf{M}^{\mathbf{3}} / \mathbf{s}\right)\end{array}$ & $\begin{array}{c}\text { Suspensão } \\
(\mathbf{m g} / \mathbf{L})\end{array}$ & $\begin{array}{c}\text { Descarga } \\
\text { Sólida } \\
(\mathbf{t} / \mathbf{d i a})\end{array}$ \\
\hline $\mathbf{1}$ & 0,42 & 4,06 & 119,00 & 483,14 & 194,39 & 40 & 701,25 \\
$\mathbf{2}$ & 0,45 & 6,30 & 140,69 & 886,35 & 398,86 & 40 & $1.378,45$ \\
$\mathbf{3}$ & 0,30 & 4,30 & 110,00 & 473,00 & 141,90 & 20 & 245,20 \\
\hline
\end{tabular}

Tabela 4. Variáveis Hidrodinâmica Seção 04. Fonte:Autor.

A vegetação do entorno permaneceu bem preservada, não apresentando nenhuma interferência antrópica. A única evidência de atividades antrópicas foi a presença de trilhas para a pesca de barranco, mas não comprometeu a desestabilização da margem.

A barra de sedimentos nessa seção também apresentou estabilização pela presença de gramíneas. Ainda na margem direita neste segmento, houve a presença de ocupações, notoriamente casa de apoio para 
pescadores ribeirinhos, no entorno a vegetação natural apresentou boas condições, bem conservada ainda na margem direita neste segmento.

Em fevereiro de 2017 o canal apresentou aumento na largura que foi de 140,69m. Concomitantemente, houve aumento na capacidade no transporte de sedimentos devido ao aumento da seção transversal que apresentou $886,35 \mathrm{~m}$ e da profundidade média de $6,3 \mathrm{~m}^{2}$. A velocidade média foi de $0,45 \mathrm{~m} / \mathrm{s}$ e a vazão atingiu $398,86 \mathrm{~m}^{3} / \mathrm{s}$. A concentração do material suspenso foi de $40 \mathrm{mg} / \mathrm{l}$ e descarga sólida de 1378,45 t/dia.

Quanto à granulometria da carga de fundo do canal, houve o predomínio de areia fina, atingindo os três períodos de monitoramentos: 98,95 \% em dezembro; 89,50\% em fevereiro e agosto de 2017 . Isso está relacionado à própria dinâmica fluvial e à variação no regime hídrico do rio Paraguai, o que influencia diretamente no transporte de sedimentos arenosos de predominância fina. O padrão de canal corrobora para a formação de feições morfológicas, como barras de sedimentos laterais e centrais, compostas por materiais grosseiros (Figura 11).

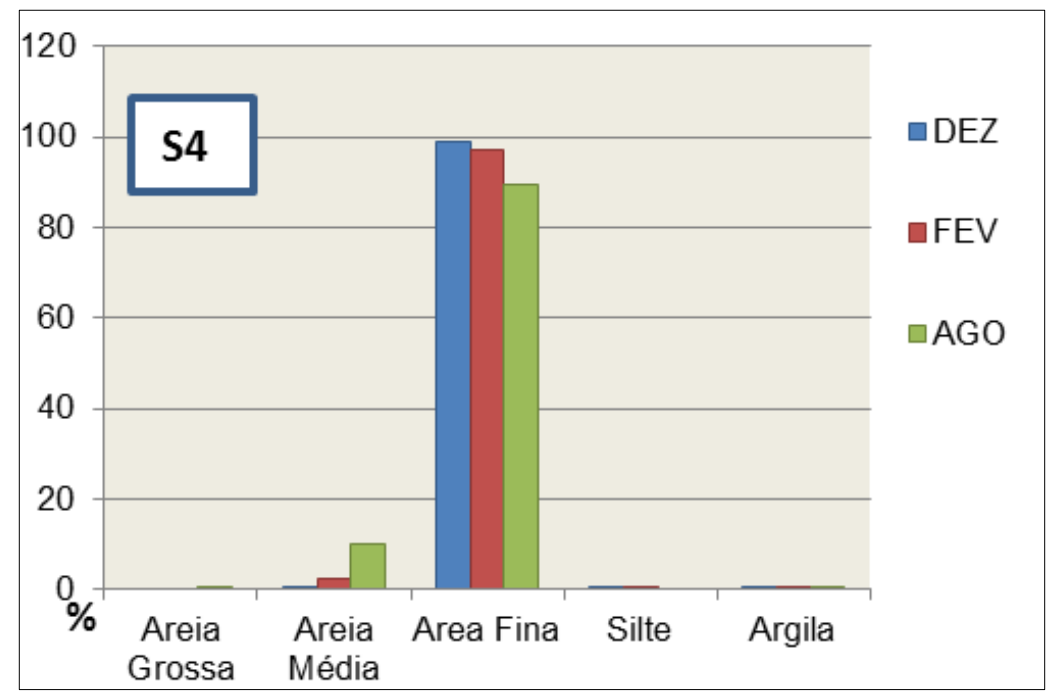

Figura 11. Porcentagens da granulometria de sedimentos de fundo. Fonte: Autor.

Em agosto de 2017, a barra de sedimentos apresentou 18 metros de largura. No canal, devido à diminuição da largura da lâmina d'água, que apresentou 110 m, a profundidade alcançou 4,30m e a área de seção transversal com $473 \mathrm{~m}^{2}$. A velocidade média do fluxo diminuiu, sendo de $0,30 \mathrm{~m} / \mathrm{s}$; a vazão foi 
de 141,90 m³/s; a concentração de sólidos suspenso foi de $40 \mathrm{mg} / \mathrm{l}$, atingindo descarga sólida de 245,20 t/dia.

d) Seção 05

Esse segmento apresentou ausência de canalizações e dragagens, o curso d'água seguiu como natural. Foram identificadas muitas áreas erodidas ao longo do canal na reta e nas curvas. A margem esquerda nesse ponto foi revestida com concreto (construção de muros de arrimo), para contenção de erosões. Ao término do muro de arrimo, ficaram evidentes intensas erosões.

A morfologia da calha apresentou alta potência hidráulica pelo fato de ter sofrido interferências diretas por ações antrópicas como aprofundamento do leito e alargamento do canal para viabilização da navegação e acesso às pousadas, modificando toda sua dinâmica (Figura 12).

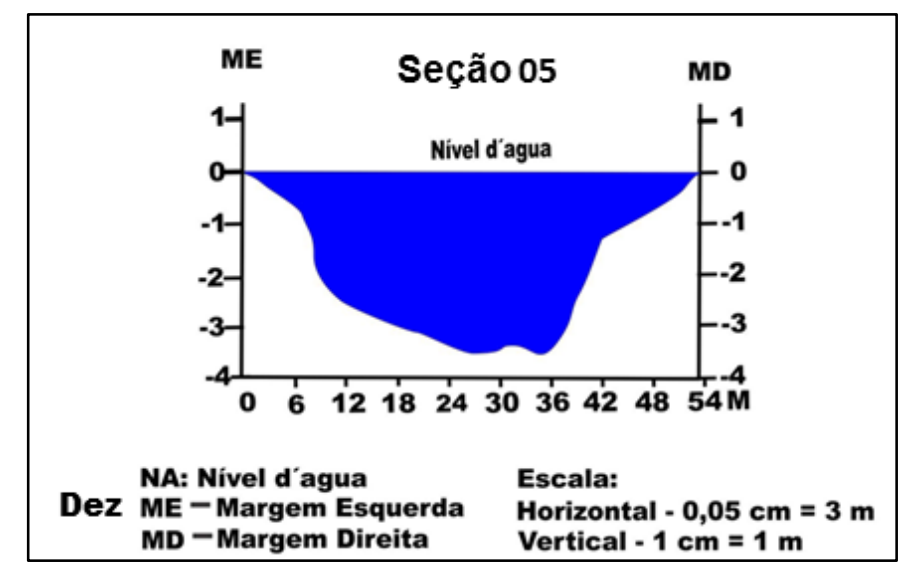

Figura 12. Perfil transversal da Baía da Palha. Fonte: Autor.

Dessa forma, a ação humana influenciou para o aumento no fluxo do canal, intensificando também a erosão fluvial. Em todos os períodos de monitoramento, constataram-se altos valores de velocidade média em relação ao rio Paraguai.

No período chuvoso, em dezembro de 2017 , a largura do canal foi de 54 metros e a profundidade média alcançou 3,55 metros, obtendo a área da seção transversal de 188,82 $\mathrm{m}^{2}$. A concentração de sólida em suspensão atingiu 40m/l e a descarga sólida atingiu 482,87 t/dia (Tabela 5). 


\begin{tabular}{|c|c|c|c|c|c|c|c|}
\hline Campo & $\begin{array}{l}\text { Velocidade } \\
\text { Média m/s }\end{array}$ & $\begin{array}{c}\text { Profundidade } \\
\text { Média }\end{array}$ & $\begin{array}{l}\text { Largura } \\
\text { (Metros) }\end{array}$ & $\begin{array}{c}\text { Área da } \\
\text { Seção } \\
\left(\mathbf{M}^{2}\right) \\
\end{array}$ & $\begin{array}{l}\text { Vazão } \\
\left(M^{3} / s\right)\end{array}$ & $\begin{array}{c}\text { Suspensão } \\
(\mathrm{mg} / \mathrm{L})\end{array}$ & $\begin{array}{c}\text { Descarga } \\
\text { Sólida } \\
\text { (t/dia) } \\
\end{array}$ \\
\hline 1 & 0,74 & 3,55 & 53,19 & 188,82 & 141,85 & 40 & 482,87 \\
\hline 2 & 0,97 & 5,96 & 63,62 & 379,18 & 367,80 & 20 & 635,56 \\
\hline 3 & 0,45 & 3,55 & 47,00 & 131,60 & 59,22 & 10 & 51,16 \\
\hline
\end{tabular}

Tabela 5. Variáveis Hidrodinâmica Seção 05. Fonte Autor.

As interferências antrópicas promovidas na calha do canal (aprofundamento) refletiram diretamente na morfologia e na dinâmica do canal, intensificando a potência e eficiência hidráulica, aumentando a velocidade do fluxo e contribuindo para um maior escoamento e aporte de sedimentos transportados. 0 canal buscou um novo ajuste ao perder seu equilíbrio; em resposta, acabou promovendo o assoreamento de canais a jusante consequentemente, apresentando uma nova morfologia.

Nesse sentido, no mês de fevereiro de 2017 a largura do canal foi de $63,62 \mathrm{~m}$ e a profundidade média de 5,96m. A área da seção transversal apresentou $379,18 \mathrm{~m}^{2}$. A velocidade média do fluxo atingiu $0,97 \mathrm{~m} / \mathrm{s}$ e a vazão foi de $367,80 \mathrm{~m}^{3} / \mathrm{s}$. A concentração de sólido suspenso foi de $20 \mathrm{mg} / \mathrm{l}$ e a descarga sólida foi de $635,56 \mathrm{t} /$ dia.

Em agosto de 2017 (período de estiagem), o canal apresentou uma largura na lâmina d'água de 47 m, com profundidade de 2,8 m. A medida da área da seção foi de 131,60 m². A velocidade média foi 0,45 m/s e vazão de 59,22 m³/s; a concentração de sólido suspenso foi de $10 \mathrm{mg} / \mathrm{l}$ e descarga sólida de 51,16 t/dia. Quando se compara a velocidade do fluxo da Baía da Palha com velocidades obtidas das seções do rio Paraguai, evidencia-se que o canal secundário possui vazão superior.

Cabe ressaltar que a mata ciliar que compõe a superfície da margem esquerda foi totalmente retirada, apresentando exposição do solo. Ficou evidente a descontinuidade da vegetação no entorno, a qual é praticamente inexistente e foi substituída pelo uso urbano e algumas áreas com pastagens, o que acaba favorecendo a atuação dos processos erosivos.

Em relação à granulometria dos sedimentos de fundo (Figura 13), dados obtidos pelas amostras coletadas no centro do canal, houve maior quantidade de areia fina nos três períodos amostrais: em dezembro de 2017 a porcentagem foi de 54,00\%, em fevereiro 86,25\% e em agosto de 2017 foi de 
$38,50 \%$, o que pode estar justificado pelo fato da margem exposta facilitar para os sedimentos dos desmoronamentos do barranco ser carregados no período de cheia para o interior do canal nessa seção.

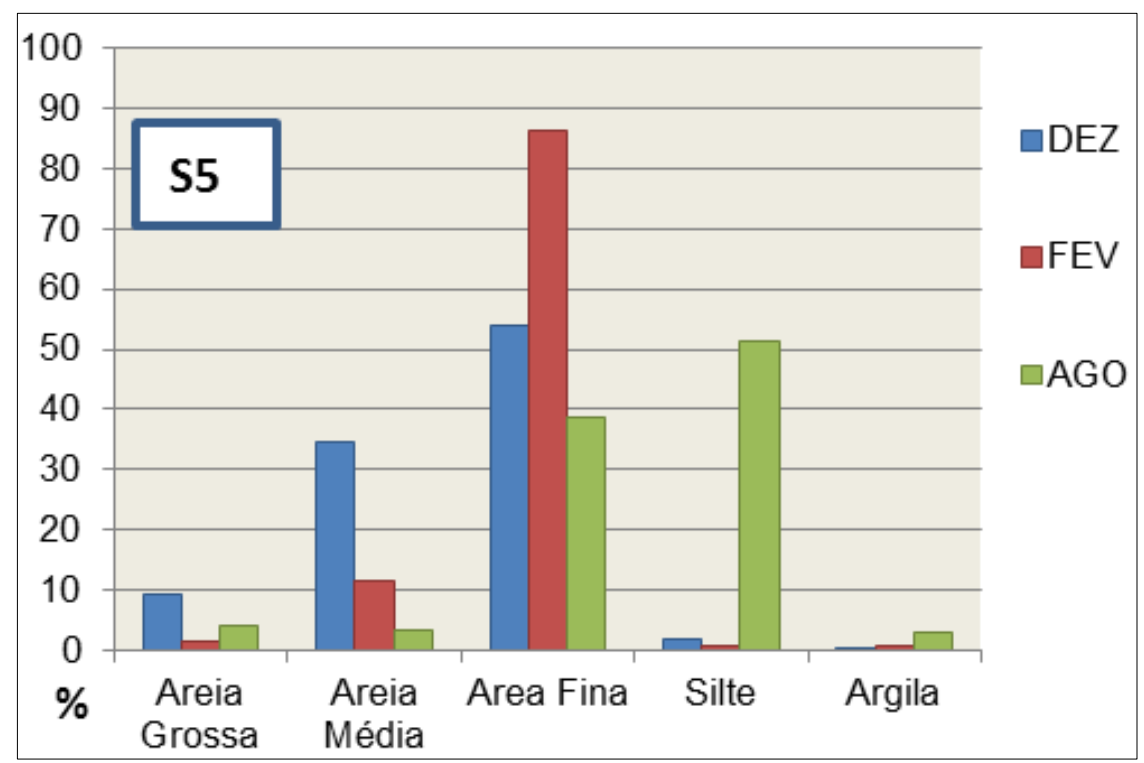

Figura 13. - Porcentagens da granulometria de sedimentos de fundo. Fonte: Autor.

A margem direita foi considerada em situação ótima, entretanto, demonstrou-se instável, porém com nenhuma evidência de deposição. Outro fator importante foi que levou a esse atingir esse parâmetro foi a ótima condição da vegetação da margem, que auxilia na sua estabilização, possuindo uma superfície coberta por espécies nativas. Nessa margem, foi identificada na vegetação a predominância de espécies como embaúba (Cecropia pachystachya) e ingá (Inga sp.). O entorno não apresentou nenhum tipo de uso por atividades humanas que possa comprometer a preservação da vegetação, não apresentando sinais de degradação.

e) Seção 06

Essa seção apresentou situação ótima em ambas às margens e por diversos parâmetros, pelo canal não apresentar nenhuma evidência de canalizações ou dragagens que possam interromper o curso do canal. A deposição dos sedimentos foi moderada, porém, resultou na origem de feições morfológicas na margem esquerda. Constatou-se a presença de deposição de material fino ou areia. 
As margens apresentaram-se estáveis; porém, também foi evidenciado no entorno o predomínio de uma vegetação nativa com árvores de pequeno e grande porte, não apresentando sinais de degradação pela ação humana.

Houve a presença de extensas barras laterais de sedimentos (BS1 e BS2) (Figura 14). As formas deposicionais estão associadas à perda de velocidade do fluxo no canal, onde esses materiais são transportados da Baía da Palha para o interior do canal no período de cheia. A perda do fluxo promove o assoreamento do canal nesse ponto, as barras são compostas por vegetação de gramíneas e mata ciliar.

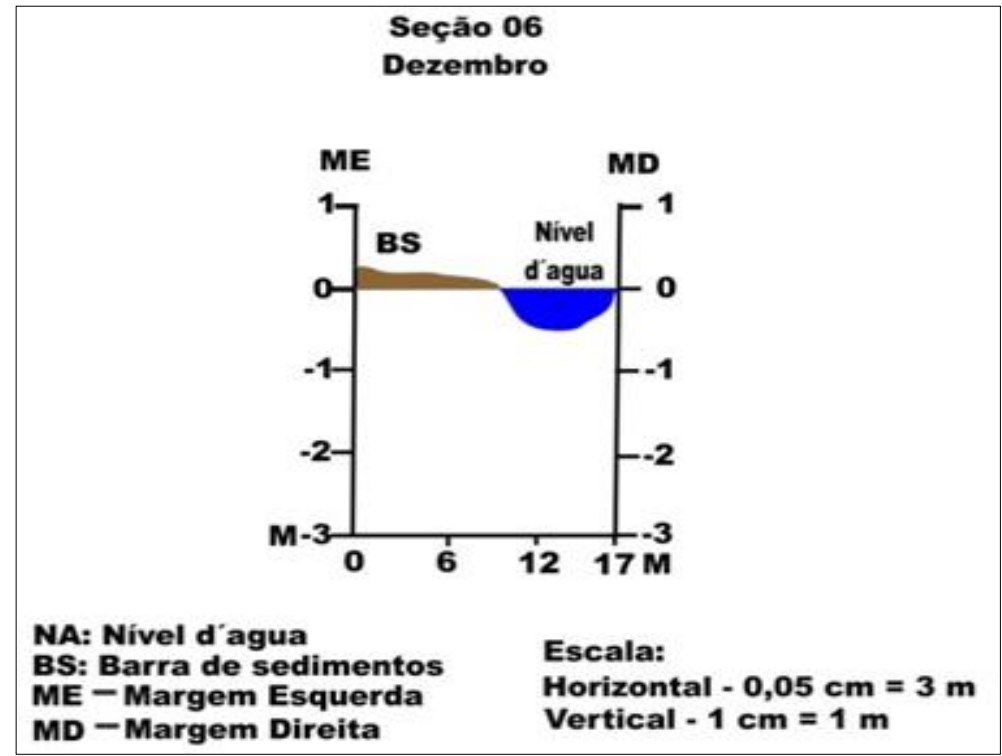

Figura 14. Perfil transversal no canal da Baía da Palha. Fonte: Autor.

No período chuvoso, no mês de dezembro de 2016, a profundidade média foi de $0,46 \mathrm{~cm}$ e a largura da lâmina d'agua de 7,17 metros com seção transversal de $3,29 \mathrm{~m}^{2}$. A velocidade média foi de $0,09 \mathrm{~m} / \mathrm{s}$, atingindo a vazão de $0,29 \mathrm{~m}^{3} / \mathrm{s}$; a concentração de sedimentos suspenso foi de $40 \mathrm{mg} / \mathrm{l}$ e carga suspensa atingiu 1,00 t/dia (Tabela 6 ).

\begin{tabular}{cccccccc}
\hline Campo & $\begin{array}{c}\text { Velocidade } \\
\text { Média m/s }\end{array}$ & $\begin{array}{c}\text { Profundidade } \\
\text { Média }\end{array}$ & $\begin{array}{c}\text { Largura } \\
(\text { Metros) }\end{array}$ & $\begin{array}{c}\text { Área da } \\
\text { Seção } \\
\left(\mathbf{M}^{2}\right)\end{array}$ & $\begin{array}{c}\text { Vazão } \\
\left(\mathbf{M}^{\mathbf{3}} / \mathbf{s}\right)\end{array}$ & $\begin{array}{c}\text { Suspensão } \\
(\mathbf{m g} / \mathbf{L})\end{array}$ & $\begin{array}{c}\text { Descarga } \\
\text { Sólida } \\
(\mathbf{t} / \mathbf{d i a})\end{array}$ \\
\hline $\mathbf{1}$ & 0,09 & 0,46 & 7,17 & 3,29 & 0,29 & 40 & 1,00 \\
$\mathbf{2}$ & 0,24 & 2,90 & 22,34 & 64,79 & 15,55 & 40 & 53,74 \\
$\mathbf{3}$ & - & - & - & - & - & - & - \\
\hline
\end{tabular}

Tabela 6. Variáveis Hidrodinâmica Seção. Fonte: Autor. 
A baixa declividade do segmento também influenciou a deposição de sedimentos finos no leito do canal, pois as baixas velocidades obtidas nos períodos de coleta indicaram que houve perda de competência no transporte de sedimentos, ou seja, o canal não teve capacidade de transportar os materiais finos, depositando-os no leito e nas margens. Dessa forma, foi constatado, na análise granulométrica de carga de fundo, o predomínio de areia fina: 97,70\% em dezembro de 2016 e 97,65\% fevereiro de 2017 (Figura 15)

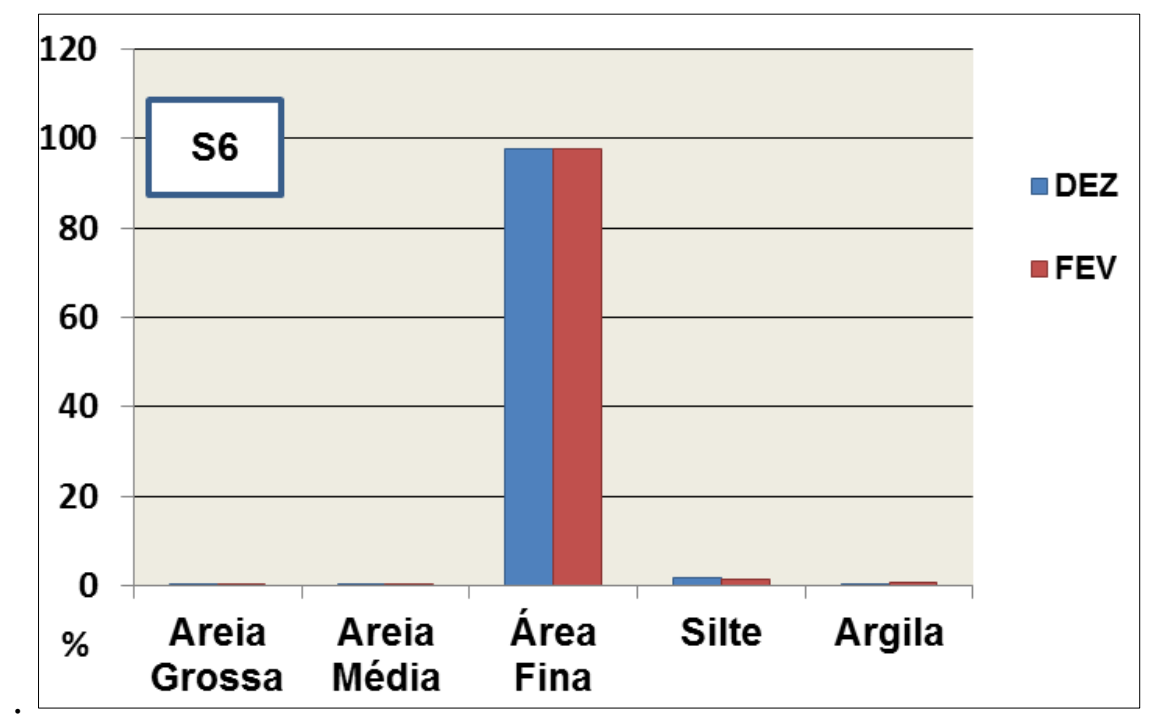

Figura 15. Porcentagens da granulometria de sedimentos de fundo. Fonte: Autor.

No período chuvoso de fevereiro, o canal é navegável e as barras de sedimentos ficaram submersas. A largura do canal aumentou e foi equivalente a 22,34m; a profundidade média foi de 2,9 m; a área da seção transversal ampliou para $64,79 \mathrm{~m}^{2}$. A velocidade média do fluxo foi de $0,24 \mathrm{~m} / \mathrm{s}$ e a vazão foi de $15,55 \mathrm{~m}^{3} / \mathrm{s}$. A concentração de sólido suspenso foi de $40 \mathrm{mg} / \mathrm{l}$ e a descarga sólida atingiu 53,74 t/dia. Cabe destacar que, no mês de agosto de 2017, a água do canal secou, permitindo o aparecimento das barras de sedimentos, com processo intenso de assoreamento ao longo da seção.

\section{f) Seção 07}

Essa seção está localizada nas proximidades da pousada Fordinho (Figura 16). A margem esquerda em certos trechos está revestida por muros de arrimo, construídos com a intenção de conter erosão. Nenhuma evidência de canalizações e/ou qualquer outra forma que possa interromper o curso d'água foi encontrada. 


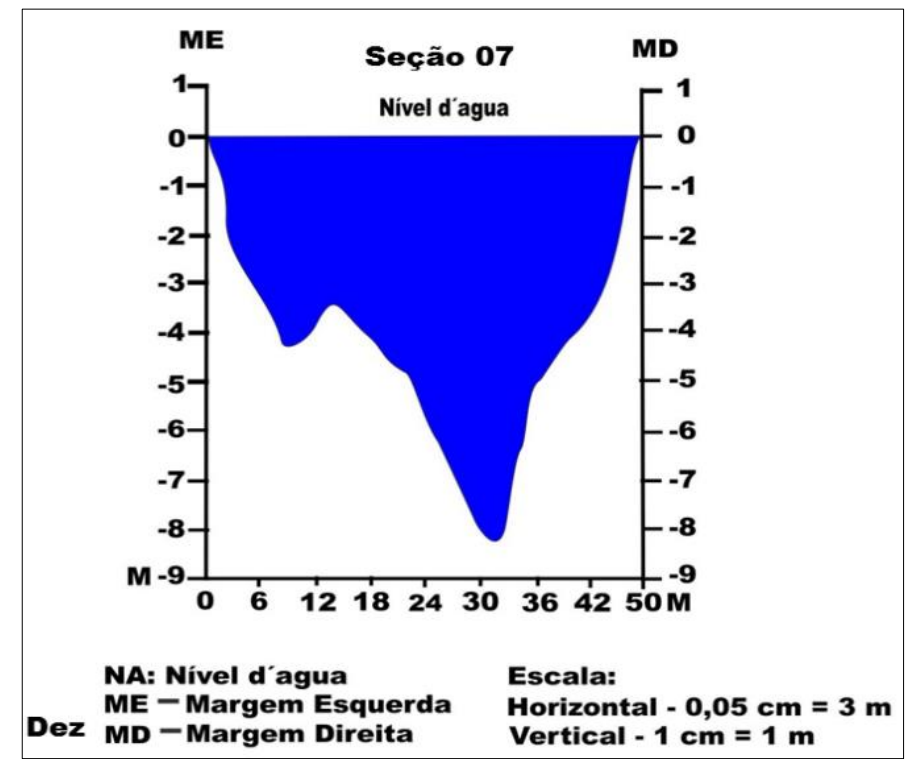

Figura 16. Perfil transversal no canal da Baía da Palha. Fonte: Autor.

A margem esquerda apresentou situação boa, porém, a cobertura vegetal nativa da do seu entorno foi totalmente retirada para a construção das pousadas, residências e casas de veraneio, dessa forma propiciou a exposição das margens, promovendo a desestabilização. Exatamente onde não há muros de contenção, a erosão é intensa e o potencial é alto no período de cheia. Outro fator que influencia o surgimento de áreas erodidas nesse segmento é o material da margem, que se demonstrou sensível (sedimentos inconsolidados). Portanto, o alto fluxo do canal, demonstrado nas variáveis hidrodinâmicas, principalmente no período de cheia, provoca intensas erosões ao longo do canal.

Dessa forma, em dezembro de 2016, o canal possuía uma média de 4,13 metros de profundidade e $50 \mathrm{~m}$ de largura, com uma área de seção de $206,50 \mathrm{~m}^{2}$. Cabe destacar que a velocidade média alcançou demonstrou altos valores decorrentes dessas ações antrópicas: $0,62 \mathrm{~m} / \mathrm{s}$; logo, a vazão mensurada foi de $128,03 \mathrm{~m}^{3} / \mathrm{s}$. A concentração de sólidos suspensos também foi elevada a $60 \mathrm{mg} / \mathrm{l}$ e 663,70 toneladas ao dia (Tabela 7).

\begin{tabular}{|c|c|c|c|c|c|c|c|}
\hline Campo & $\begin{array}{l}\text { Velocidade } \\
\text { Média m/s }\end{array}$ & $\begin{array}{c}\text { Profundidade } \\
\text { Média }\end{array}$ & $\begin{array}{l}\text { Largura } \\
\text { (Metros) }\end{array}$ & $\begin{array}{c}\text { Área da } \\
\text { Seção } \\
\left(M^{2}\right)\end{array}$ & $\begin{array}{l}\text { Vazão } \\
\left(M^{3} / \mathbf{s}\right)\end{array}$ & $\begin{array}{c}\text { Suspensão } \\
(\mathrm{mg} / \mathrm{L})\end{array}$ & $\begin{array}{c}\text { Descarga } \\
\text { Sólida } \\
\text { (t/dia) }\end{array}$ \\
\hline 1 & 0,62 & 4,13 & 43,91 & 181,34 & 128,03 & 60 & 582,83 \\
\hline 2 & 0,65 & 5,73 & 45,80 & 262,43 & 193,67 & 40 & 589,49 \\
\hline 3 & 0,51 & 3,10 & 43,00 & 133,30 & 67,98 & 10 & 58,73 \\
\hline
\end{tabular}

Tabela 7. Variáveis Hidrodinâmica Seção 07 Fonte: Autor 
A margem direita apresentou condições ótimas devido a uma vegetação composta por espécies nativas, bem preservadas, sem exposição e com mínima evidência de ação antrópica. Entretanto, apresentou-se moderadamente instável com intensas erosões, algumas árvores apresentaram raízes expostas e inclinações ocasionadas pela erosão, é notório que o potencial é alto durante as cheias. Nessa margem, ocorre erosão por solapamento basal. Na parte inferior, os sedimentos são transportados, provocando a queda do bloco da parte superior da margem.

Em fevereiro de 2017, a largura do canal foi de 52 metros de largura e a profundidade média foi de 5,73 m, obtendo a área da seção de $297,96 \mathrm{~m}^{2}$. A velocidade do fluxo alcançou $0,65 \mathrm{~m} / \mathrm{s} ; \log 0$, a vazão foi de 193,67 m³ $/ \mathrm{s}$. A concentração de sólido suspenso atingiu 40mg/l e carga sólida foi de 669,332 toneladas ao dia.

A concentração elevada de sólido suspenso nos meses de dezembro de 2016 e fevereiro de 2017 está associada ao uso da margem esquerda e à intensidade de chuva que ocorreu nesse período. Quanto ao uso, a mata ciliar foi retirada para usos diversos (pousadas, pastagem e residências com quintais). Nos períodos chuvosos, sedimentos são levados ao leito pelo escoamento superficial. Em relação à granulometria de sedimentos de fundo, predominaram maiores porcentagens de sedimentos finos: $83,07 \%, 96,06 \%$ e $83,17 \%$ (Figura 17).

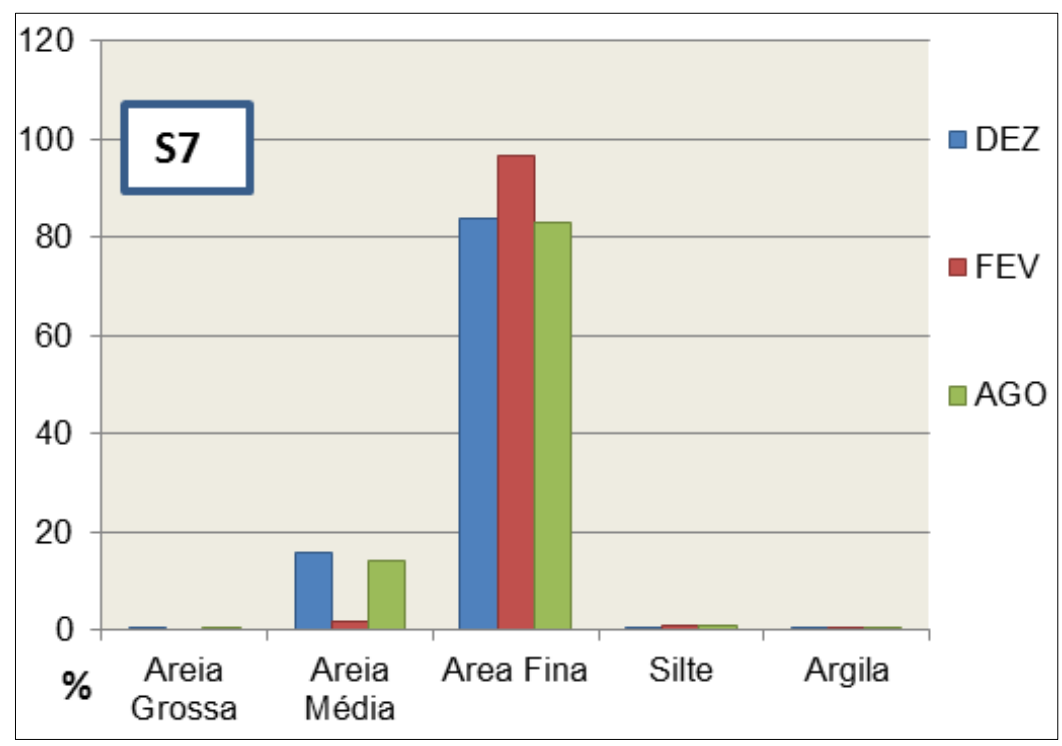

Figura 17. Porcentagens da granulometria de sedimentos de fundo Fonte: Autor 
A erosão das margens contribui para aumentar a carga de sedimentos finos, os quais, após serem arrancados do barranco são transportados e depositados no interior do canal nos períodos chuvosos. Devido a intensas erosões ao longo da seção, alguns trechos foram colocados: os revestimentos de concreto chamados de muros de arrimo para contenção dos intensos desmoronamentos. Cabe destacar que esta seção transporta sedimentos finos para a jusante e para a seção 08.

No período de estiagem, as variáveis apresentaram índices menores que no período de cheia, o que está relacionado a influência sazonal do rio Paraguai. Em agosto de 2017, o canal possuía 43m de largura e $3,31 \mathrm{~m}$ de profundidade média; a velocidade média atingiu cerca $0,51 \mathrm{~m} / \mathrm{s}$, apresentando vazão de $67,98 \mathrm{~m}^{3} / \mathrm{s}$. A concentração de sólido suspenso foi de $10 \mathrm{mg} / \mathrm{l}$, com uma descarga sólida de 58,73 t/dia.

\section{g) Seção 08}

Essa seção está localizada no canal principal do rio Paraguai, nas proximidades do complexo de pousadas (02 de Ouro, San Marino e Sadao), no fim do perímetro urbano da cidade de Cáceres. Ambas as margens de acordo com a aplicação do protocolo estão em ótimas situações, a margem esquerda apresenta cobertura vegetal preservada, porém apresentou evidências de erosões, mantendo-se instável. Cabe destaca que os processos erosivos no rio Paraguai ocorrem de forma natural.

O canal principal nesse ponto faz confluência com os canais secundários da Palha e apresentou ausência de dragagem, canalização ou qualquer tipo de interferência que possa afetar o curso natural do canal.

A desembocadura da Baía da Palha exerce influência no canal principal, mantendo um fluxo turbulento na confluência do canal principal com a saída da Baía da Palha. Dessa forma, no início do período chuvoso, em dezembro de 2106 , a largura do canal foi de $117 \mathrm{~m}$ e a profundidade média de 5,40 , obtendo uma área de seção transversal 631,80 m², local onde houve maior concentração de sólido em suspensão, que atingiu $60 \mathrm{mg} / \mathrm{l}$ e a descarga sólida atingiu 1572,09 t/dia. Ao mesmo tempo, também foi verificado um aumento significativo da vazão que alcançou $303,26 \mathrm{~m}^{3} / \mathrm{s}$. 
Na margem direita, mais de 90\% da vegetação é nativa, com ausência de qualquer tipo de ocupação que possa interromper o crescimento natural da cobertura vegetal e/ou plantas. Apresenta também deposição moderada de areia ou sedimentos finos em barras recentes e antigas. Há a presença de formação de uma extensa barra de sedimentos na margem direita de 10 metros, cujo material é proveniente de depósitos em margem convexa pela morfologia da calha ser típica de canal de padrão meandrante. As porcentagens de sedimentos finos ficaram constatadas nas análises granulométricas, nos três períodos de monitoramento, obtendo-se porcentagens de areia fina, sendo em dezembro 98,10 \%, em fevereiro 86,95 e em agosto de 2017 foi de 86,95 (Figura 18).

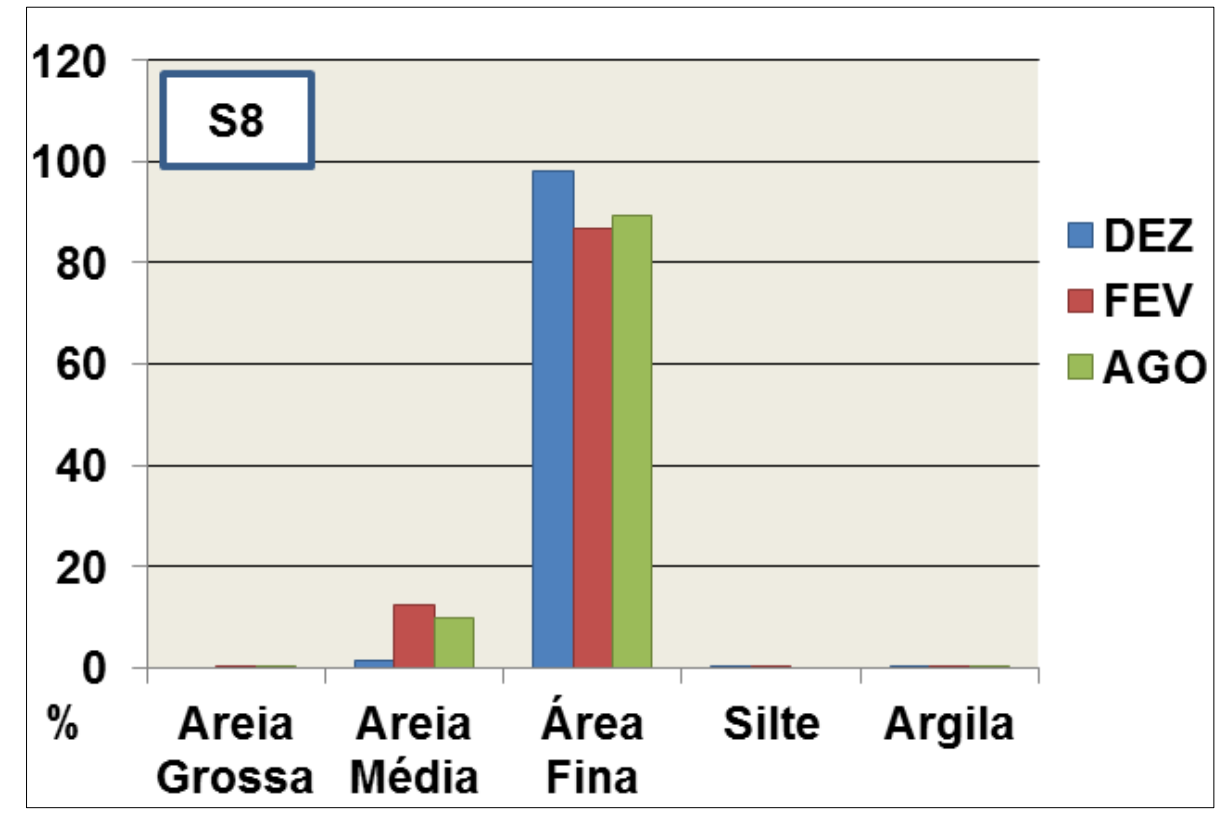

Figura 18. Porcentagens da granulometria de sedimentos de fundo Fonte: Autor

Em agosto de 2017, o canal apresentou largura em sua lâmina d'agua de 109m. Sua profundidade atingiu 5,9m com uma área de seção de $643,10 \mathrm{~m}^{2}$. O canal mensurou em sua velocidade média de fluxo $0,33 \mathrm{~m} / \mathrm{s}$; logo, sua vazão atingiu $212,22 \mathrm{~m}^{3} / \mathrm{s}$. A concentração de material em suspensão nesse período foi inferior, atingindo $20 \mathrm{mg} / \mathrm{l}$ e a carga suspensa foi de 366,71 t/dia. A barra de sedimentos nesse mês apresentou 150 metros de extensão e 21 metros de largura (Figura 19). 


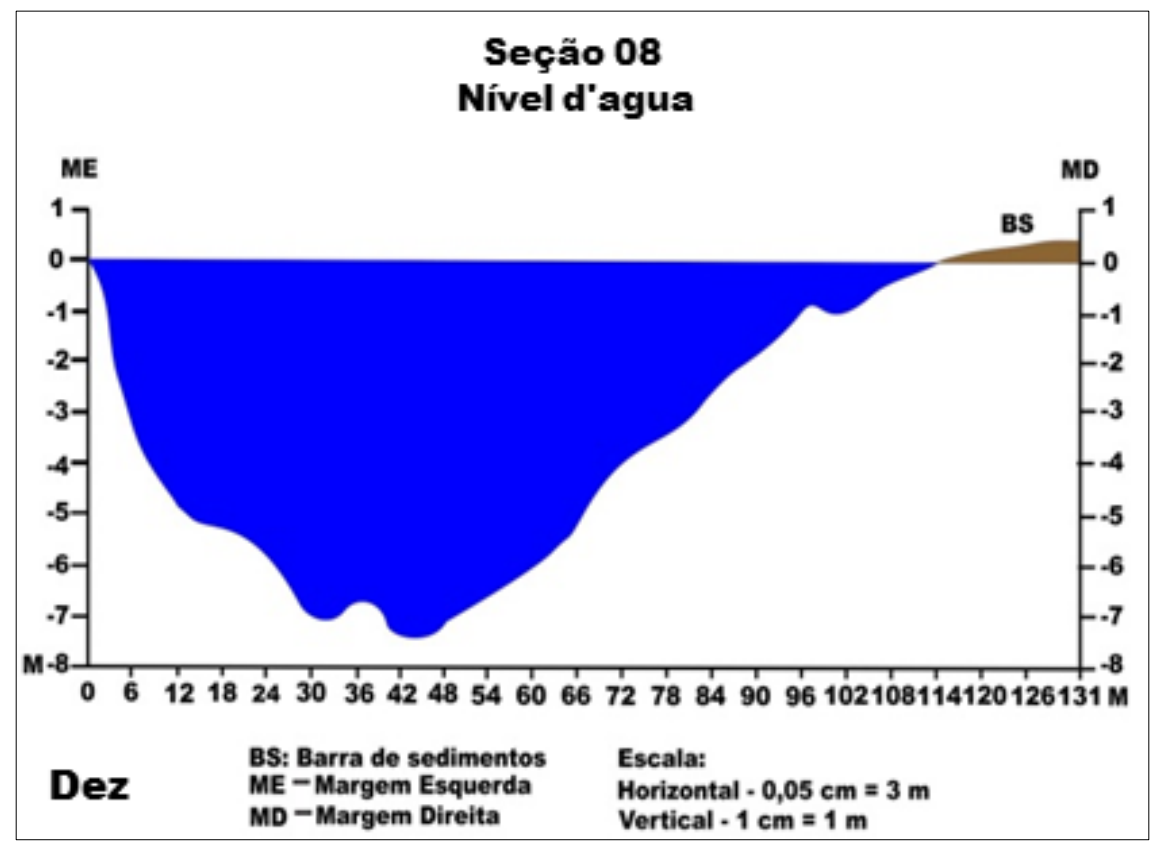

Figura 19. Perfil transversal na desembocadura da Baía da Palha no canal Principal Fonte: Autor

Os canais da Baía da Palha são abastecidos pelo canal principal a jusante e a montante, que nos períodos de cheias apresentaram-se mais ativos, com maiores velocidades no fluxo. Esse fator contribui para transportar sedimentos finos para o interior do canal principal, aumentando a concentração de carga de fundo e materiais suspensos.

Dessa forma, em fevereiro de 2017, a profundidade média do canal foi de 7,06 metros; a largura da lâmina d'água apresentou 117 metros, com a área da seção de 910,94m². A velocidade média do fluxo foi de $0,74 \mathrm{~m} / \mathrm{s}$ e a vazão mensurada foi de $673,95 \mathrm{~m}^{3} / \mathrm{s}$. A concentração de material em suspensão atingiu $40 \mathrm{mg} / \mathrm{l}$ e a carga suspensa 2.329,17 t/dia (Tabela 8).

\begin{tabular}{cccccccc}
\hline Campo & $\begin{array}{c}\text { Velocidade } \\
\text { Média m/s }\end{array}$ & $\begin{array}{c}\text { Profundidade } \\
\text { Média }\end{array}$ & $\begin{array}{c}\text { Largura } \\
(\text { Metros) }\end{array}$ & $\begin{array}{c}\text { Área da } \\
\text { Seção } \\
\left(\mathbf{M}^{2}\right)\end{array}$ & $\begin{array}{c}\text { Vazão } \\
\left(\mathbf{M}^{\mathbf{3}} / \mathbf{s}\right)\end{array}$ & $\begin{array}{c}\text { Suspensão } \\
(\mathbf{m g} / \mathbf{L})\end{array}$ & $\begin{array}{c}\text { Descarga } \\
\text { Sólida } \\
(\mathbf{t} / \mathbf{d i a})\end{array}$ \\
\hline $\mathbf{1}$ & 0,48 & 5,40 & 117,00 & 631,80 & 303,26 & 60 & $1.572,09$ \\
$\mathbf{2}$ & 0,74 & 706 & 129,00 & 910,74 & 673,95 & 40 & $2.329,17$ \\
$\mathbf{3}$ & 0,33 & 5,90 & 119,00 & 643,10 & 212,22 & 20 & 366,71 \\
\hline
\end{tabular}

Tabela 8 Variáveis Hidrodinâmica Seção 08. Fonte: Autor 
Cabe destacar que o fluxo d'agua nessa seção no período de cheia ocorre também em direção ao interior dos canais pelo canal principal, que distribui parte do fluxo, abastecendo os canais na Baía da Palha e tornando-os mais ativos. Esse processo está relacionado a baixa declividade e ao fato da margem esquerda ser (côncava), ou seja a erosão é mais profunda.

Vale ressaltar que o tamanho da área da seção, profundidade, vazão, nesse segmento, apresentou valores superiores em relação às seções monitoradas no interior da Baía da Palha. Outros fatores que também podem ter influenciado para que fosse encontrada alta concentração de sedimentos suspensos nessa seção no mês de dezembro estão relacionados aos diversos tipos de uso a montante, mais precisamente aos materiais vindos da Baía da Palha, provenientes da exposição do solo pelo uso urbano e pastagens.

A retirada da cobertura vegetal (mata ciliar) promoveu a exposição do solo e, consequentemente, o aumento de erosões de margem, contribuindo para maior produção de sedimentos, carreados para o interior dos canais.

h) Seção 09

A seção 09 está localizada na Baía dos Passarinhos, afastada das áreas mais antropizada. A área possui características de baía, abastecida pelo canal principal do rio Paraguai nos ciclos de cheia. A baía apresentou baixa influência antrópica e não foi encontrada nenhuma evidência de que o leito tenha sido explorado por atividades humanas, tampouco interferências que afetassem o curso d'água.

Dessa forma, as baixas velocidades indicam que a morfologia da calha da baía possui um fluxo lêntico, indicando baixa capacidade de transporte de sedimentos. No mês de dezembro de 2016, o canal apresentou 31 metros de largura (Figura 20), a profundidade média foi de $2,1 \mathrm{~m}$ e a área de seção é de $65,10 \mathrm{~m}^{2}$. A velocidade média foi de $0,07 \mathrm{~m} / \mathrm{s}$ e a vazão de $4,55 \mathrm{~m}^{3} / \mathrm{s}$. A concentração de sólido suspenso foi de $20 \mathrm{~m} / \mathrm{g}$ e a descarga sólida foi de 7,86 t/dia. 


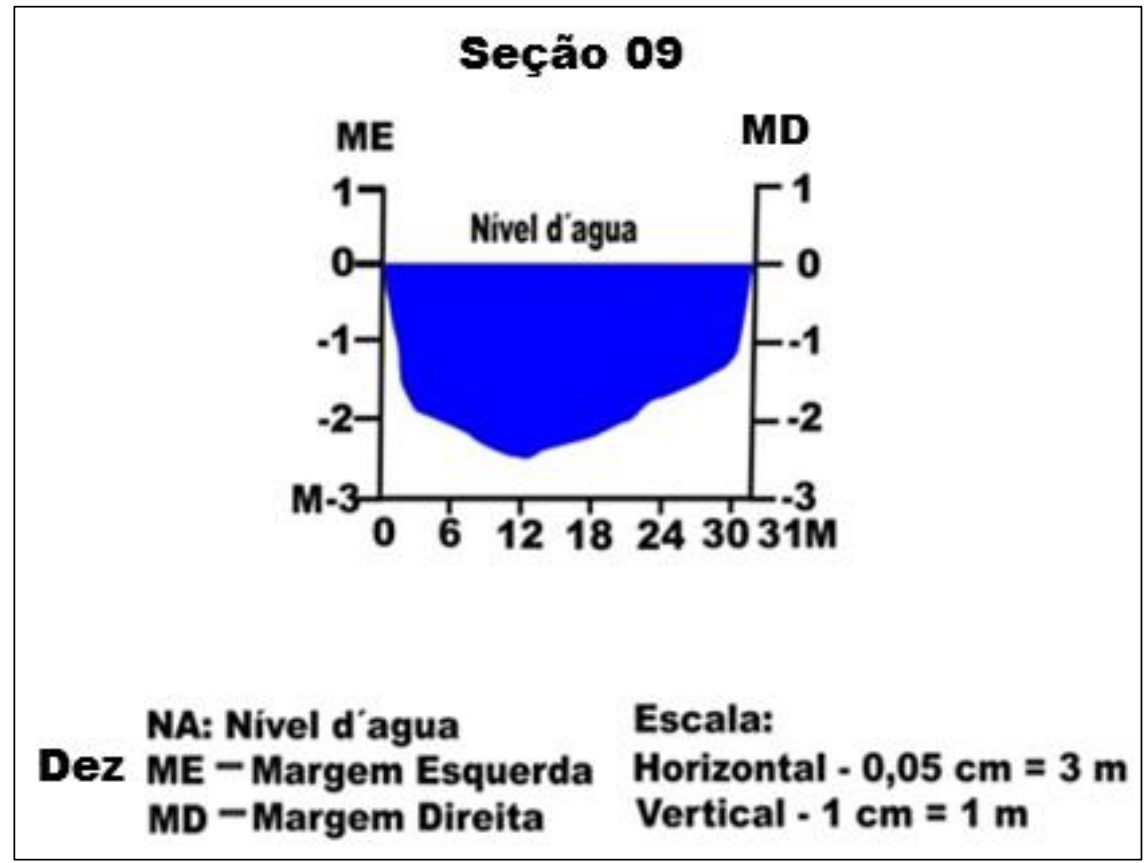

Figura 20. Perfil transversal da Baía dos Passarinhos. Fonte: Autor

Em fevereiro de 2017, o canal aumentou para 32,82 m. Sua largura e profundidade média foram de 4,90 m, obtendo a área da seção de $160,82 \mathrm{~m} 2$. A velocidade média do fluxo foi de $0,21 \mathrm{~m} / \mathrm{s}$ e a vazão de $33,77 \mathrm{~m}^{3} / \mathrm{s}$, a carga suspensa atingiu $20 \mathrm{mg} / \mathrm{l}$, a descarga sólida perfez 58,36 t/dia (Tabela 9).

\begin{tabular}{cccccccc}
\hline Campo & $\begin{array}{c}\text { Velocidade } \\
\text { Média m/s }\end{array}$ & $\begin{array}{c}\text { Profundidade } \\
\text { Média }\end{array}$ & $\begin{array}{c}\text { Largura } \\
\mathbf{( M e t r o s )}\end{array}$ & $\begin{array}{c}\text { Área da } \\
\text { Seção } \\
\left(\mathbf{M}^{2}\right)\end{array}$ & $\begin{array}{c}\text { Vazão } \\
\left(\mathbf{M}^{\mathbf{3}} / \mathbf{s}\right)\end{array}$ & $\begin{array}{c}\text { Suspensão } \\
(\mathbf{m g} / \mathbf{L})\end{array}$ & $\begin{array}{c}\text { Descarga } \\
\text { Sólida } \\
\mathbf{( t / d i a )}\end{array}$ \\
\hline $\mathbf{1}$ & 0,07 & 2,10 & 30,45 & 63,94 & 4,55 & 20 & 7,72 \\
$\mathbf{2}$ & 0,21 & 4,90 & 32,82 & 160,82 & 33,77 & 20 & 58,36 \\
$\mathbf{3}$ & 0,09 & 1,12 & 27,00 & 30,24 & 2,72 & 10 & 2,35 \\
\hline
\end{tabular}

Tabela 14. Variáveis Hidrodinâmica Seção 9. Fonte: Autor

No período monitorado de agosto de 2017 , a largura do canal diminuiu para 27 metros, a profundidade foi de 1,12 metros e a área da seção foi de 30,24 metros. A velocidade média do fluxo foi de 0,09 m/s, enquanto a vazão foi de $2,72 \mathrm{~m}^{3}$. A concentração de sólidos suspensos foi $10 \mathrm{mg} / \mathrm{l}$ e a carga suspensa foi de 2,35 t/dia. Quanto à carga de fundo na análise granulométrica de material de fundo, demonstrou alta predominância de silte em dezembro (58,55\%), fevereiro (69,7\%). 0 maior valor foi identificado, contudo, foi em agosto $(77,80 \%)$. Os sedimentos de fundo possuem semelhança com o material da margem acinzentado (Figura 21). 


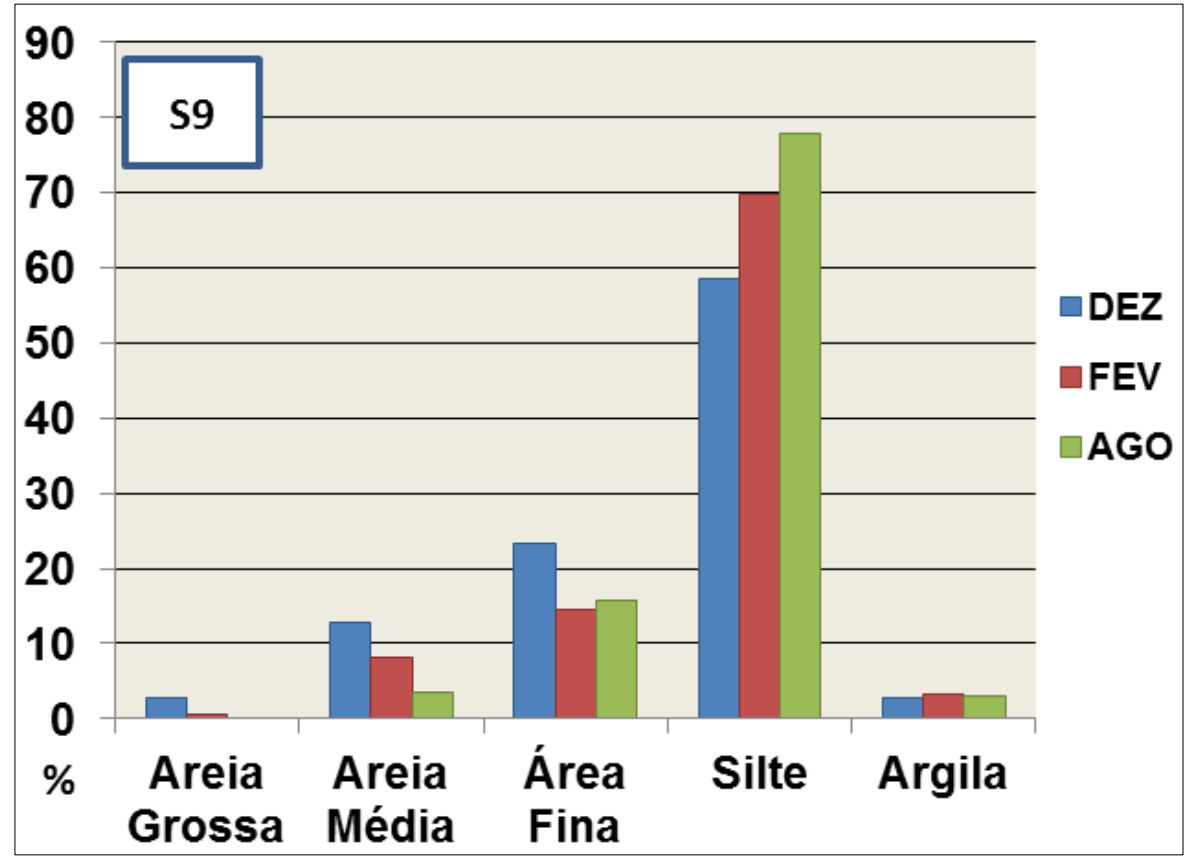

Figura 21. Porcentagens da granulometria de sedimentos de fundo. Elaborado por AUTOR

A vegetação do entorno das margens influencia para as ótimas condições ecológicas e morfológicas dessa seção, pois praticamente não sofreu influência antrópica, mantendo-se bem preservada, demonstrou-se composta por espécies nativas sem nenhuma evidência de pastagens e/ou presença de áreas para cultivo. Portanto esse ponto de acordo com aplicação dos protocolos e das variáveis hidrodinâmicas apresentou em ótimas condições.

\section{CONSIDERAÇÕES FINAIS}

As metodologias empregadas foram pertinentes para mensurar e avaliar os processos hidrossedimentológicos, e a atual condição ambiental das margens, onde utilizou-se do monitoramento a partir de variáveis hidrodinâmicas, seções de batimetrias, e aplicação de protocolos de avaliação rápida de rios.

Houve predominância de areia fina na maioria seções monitoradas, exceto na seção 9, na qual predominou silte, essa tendência é predominante em rios meandrantes, porém ações antrópicas colaboram para que o material fino seja transportado e depositado em áreas mais baixas promovendo assoreamentos e mudanças ao longo da calha fluvial. 
Os processos formadores das feições positivas (barras de sedimentos, cordões marginais, diques marginais e ilhas) e negativas (baías, canais secundários e lagoas) estão associados a interferências antrópicas e à própria dinâmica fluvial do rio Paraguai e às suas características geoambientais, como padrão do canal (meandrante), regime hídrico (precipitações), declividade (área plana), composição granulométrica do material da margem.

Os resultados obtidos a partir do monitoramento dos processos hidrossedimentológicos e através dos Protocolos, mostraram que o leito fluvial foi alterado pelas interferências antrópicas (retirada das matas ciliares, uso das margens, aprofundamento da calha,). Essas intervenções influenciaram no aumento na velocidade do fluxo, principalmente nas seções 2,5 e 7 , contribuindo para evolução lateral e intensificação dos processos erosivos.

Portanto, recomendam-se estudos científicos mais detalhados, relacionados à dinâmica fluvial e à interface da ocupação urbana com a qualidade ambiental do rio Paraguai, a fim de subsidiar futuros planejamento e gestão socioambientais, tanto no âmbito regional quanto local.

\section{REFERÊNCIAS}

CARVALHO, Newton. Oliveira.; FILIZOLA JÚNIOR, Naziano.Pantoja.; SANTOS, Paulo.Marcos.Coutinho.; LIMA, Jorge.Enoch.Furquim.Werneck. Guia de Práticas Sedimentométricas. Brasília: ANEEL, 154p. 2000.

CHRISTOFOLETTI, Antônio.; Geomorfologia (51): a mecânica do transporte fluvial. Universidade de São Paulo - USP, São Paulo: Instituto de Geografia, 1977.

CUNHA, Sandra. Baptista.; Morfologia dos Canais Urbanos, In: Ambientes e Sedimentos. (Org) POLETO, Carlos. Porto Alegre: ABRH, p 329-360, 2008.

EMBRAPA - Empresa Brasileira de Pesquisa Agropecuária. Manual de Métodos de Análises de Solos. Rio de Janeiro, 2. ed.: 212 p. Embrapa Solos, 1997.

LEOPOLD, Luna. Bergere.; MADDOCK, Junior; Thomas. The hydraulic geometric os stream channels and some physiographic implications.13.S. Geol. Surv. Prof. Paper 252: 57 p, 1953.

ROCHA, Paulo; César. Geomorfologia e Áreas Inundáveis na Planície Fluvial do Alto rio Paraná. Rev. Geogr. Acadêmica v.5, n.1, p. 98-117, 2011.

RODRIGUES, Aline. Sueli. Lima.; MALAFAIA, Guilherme.; COSTA, Adivane. Terezinha.; JUNIOR, Hermínio. Arias. Nalini. Adequação e avaliação da aplicabilidade de um Protocolo de Avaliação Rápida na bacia do rio Gualaxo do Norte, 
Leste-Sudeste do Quadrilátero Ferrífero. MG, Revista Ambiente \& Água - An Interdisciplinary Journal of Applied Science. v. 7, n.2, p. 231-244, 2012 .

SILVA, Edenio. Sebastião. Faria.; Dinâmica Fluvial Do Rio Paraguai No Segmento Entre Furado Do Touro E Passagem Velha, Cáceres- Mato Grosso. 2012. 113 f. Dissertação (Mestrado em Ciências Ambientais), Universidade do Estado de Mato Grosso - UNEMAT. Cáceres - MT. 2012.

SILVA, Edenio. Sebastião. Faria.; SOUZA, Célia. Alves.; LEANDRO, Gustavo. Roberto. Santos.; ANDRADE, Leila. Nalis.Prudencio. Silva.; GABIATI, Carla.; Evolução das feições morfológicas do rio Paraguai no Pantanal de Cáceres - Mato Grosso. Revista Brasileira de Geomorfologia. v.13, n.4, p.435-442, 2012.

SOUZA, Célia. Alves.; Dinâmica do corredor fluvial do rio Paraguai entre a cidade de Cáceres e a Estação Ecológica da ilha de Taiamã-MT. 2004. 173 f. Tese (Doutorado em Geografia) - Centro de Ciências Matemáticas e da Natureza, Universidade Federal do Rio de Janeiro - UFRJ, Rio de Janeiro, 2004.

SUGUIO, Kentiro. Introdução à sedimentologia. São Paulo: Edgard Blücher, p. 307, 1973.

SUGUIO, Kentiro.; BIGARELLA, José. João. Ambientes fluviais. 2 ed. Florianópolis: Ed. da UFSC, 1990. 